\title{
Scientific Meeting of the Faculty of Accident and Emergency Medicine, Royal College of Physicians, London, 3-4 December 1999
}

\section{Prize Session, 3 December 1999}

\section{A descriptive study of a chest pain obser-} vation unit in a UK hospital

$\mathrm{S}$ W GOODACRE, F P MORRIS, K ANGELINI, J A ARNOLD Accident and Emergency Department, Northern General Hospital, Herries Road, Sheffield S5 7AU

Background - The chest pain observation unit (CPOU) has been developed in the United States as a safe and cost effective alternative to hospital admission for patients attending with chest pain. We aimed to reproduce a CPOU protocol in a United Kingdom hospital, describe its function, and evaluate its safety.

Method -A protocol consisting of 4 to 6 hours continuous ST monitoring and serial electrocardiograms (ECGs), CK-MB (mass), and troponin $\mathrm{T}$ measurement and, when appropriate, exercise stress testing was made available for patients attending $\mathrm{A} \& \mathrm{E}$ with chest pain who were at low risk of myocardial infarction. Criteria for admission or discharge were drawn up and applied. All patients were followed upthose admitted by case note review, and those discharged by clinical assessment, ECG, and troponin $\mathrm{T}$ measurement at 72 hours after discharge.

Results-To date 200 patients have been assessed according to the protocol. Mean age was 53 years, $60 \%$ were male, and $22 \%$ were known to have ischaemic heart disease; $35(18 \%)$ were admitted and $165(83 \%)$ discharged. Reasons for admission were positive enzyme tests for 12 patients (34\%), serial ECG changes for eight (23\%), positive or inconclusive stress tests for $11(31 \%)$, and other reasons for four $(11 \%)$. A final diagnosis of myocardial infarction was made in seven (3.5\%). $90 \%$ of the discharged patients attended for follow up. No evidence of missed pathology was found at 72 hour follow up.

Conclusion-The US model of the chest pain observation unit can be safely reproduced in the UK. Studies are now required to determine its effectiveness and cost effectiveness compared with routine UK practice.

In vitro evaluation of the effect of haemodilution with crystalloid and colloid solutions on coagulation profile measured by Sonoclot analysis

E V BRAZIL, T J COATS

Academic Unit, Accident and Emergency Department, Royal London NHS Trust, Whitechapel, London E1 1BB

Introduction-The "Sonoclot analyser" is a device used to measure the quality of a devel-

Table 1 Rate and peak measurements for control and the various blood dilutions

\begin{tabular}{|c|c|c|c|c|c|c|c|c|c|}
\hline & \multirow[b]{2}{*}{ Control } & \multicolumn{2}{|c|}{$10 \%$ Solution } & \multicolumn{2}{|c|}{$20 \%$ Solution } & \multicolumn{2}{|c|}{$40 \%$ Solution } & \multicolumn{2}{|c|}{$60 \%$ Solution } \\
\hline & & $C R^{\star}$ & $C O L^{\star}$ & $C R$ & $C O L$ & $C R$ & $C O L$ & $C R$ & $C O L$ \\
\hline Peak (s) & 982 & 679 & $1052 \dagger$ & 686 & $1568 \dagger$ & 586 & $1870 \dagger$ & 847 & $2368 \dagger$ \\
\hline Rate & 20.3 & 24 & $19.7 \ddagger$ & 24.5 & $17.6+$ & 22.4 & $12.3 t$ & 17.6 & $7.27 \dagger$ \\
\hline
\end{tabular}

${ }^{\star} \mathrm{CR}=0.9 \%$ Sodium chloride $\mathrm{COL}=$ gelofusine.

$\dagger \mathrm{p}<0.004 ; \ddagger \mathrm{p}=0.0371$ Wilcoxon’s signed ranks test.

oping blood clot. It measures the changing resistance to movement imposed by a developing clot on a small probe vibrating at an ultrasonic frequency in a coagulating blood sample. Two commonly used measurements derived from Sonoclot analysis are the rate of fibrin formation from fibrinogen (rate) and the time to reach maximum resistance (peak) This device has not previously been used to investigate the effect of haemodilution on blood coagulation.

Aim - The study was designed to test the hypothesis that colloid (gelofusine) haemodilution causes a reduction in clot quality measured by Sonoclot analysis compared with crystalloid $(0.9 \%$ sodium chloride) haemodiluted blood.

Methods-With local ethics committee approval, each of 12 volunteers had nine fresh blood samples taken from a free flowing upper limb vein and added to solution (colloid or crystalloid) in vitro to make a $10 \%, 20 \%$, $40 \%$, and $60 \%$ solution. One undiluted sample was taken as control.

Results-Table 1 shows rate and peak measurements for control and the various blood dilutions. There was a highly significan decrease in clot quality for colloid versus crystalloid diluted blood for all haemodilutions. Blood diluted with crystalloid solution showed increased coagulability compared with control blood but returned towards normal at higher haemodilutions.

Conclusion-Blood diluted with gelofusine in vitro causes a reduction in clot quality compared with crystalloid diluted blood.

Use of carbon monoxide in a bedside system for measuring circulating blood volume

B A FOËX ${ }^{\star}$, J DINGLEY ${ }^{\star \star}$, R A LITTLE ${ }^{\star}$

${ }^{\star}$ North Western Injury Research Centre, Manchester, and ${ }^{\star *}$ Department of Anaesthetics and Intensive Care Medicine, University Hospital of Wales, Cardiff

Objective - To evaluate the repeatability of the carbon monoxide (CO) method for estimating blood volume (BV). Techniques currently used, such as radioisotope labelling or indicator dye dilution, need laboratory support. This new technique, using carbon monoxide as a label, and incorporating a novel rebreathing system driven by a ventilator, would be suitable for bedside use in an ICU.

Methods-Six normovolaemic pigs were anaesthetised and mechanically ventilated. Each was given an appropriate volume of $\mathrm{CO}$ 
change in pain score per hour for morphine was $-12.04(95 \% \mathrm{CI}-13.81$ to -10.27$)$ and -11.27 for ketorolac $(95 \%$ CI -12.82 to $-9.71 ; \mathrm{p}=0.54)$. With activity, the overall rate of change in pain score per hour at rest was -1.0 for morphine $(95 \% \mathrm{CI}-1.3$ to -0.7$)$ and -1.2 for ketorolac $(95 \% \mathrm{CI}-1.9$ to $-0.5 ; \mathrm{p}=$ $0.003)$. Adverse effects were noted in $4 / 75$ patients receiving ketorolac and $65 / 73$ patients receiving morphine (odds ratio 0.007; $\mathrm{p}<0.0001)$. Mean patient satisfaction scores with ketorolac and morphine were 5.9 (1.0) and $4.8(1.6)(\mathrm{p}<0.0001)$, and the mean time to discharge was 26 minutes shorter with ketorolac than morphine $(\mathrm{p}<0.02)$. The overall mean costs per person for ketorolac and morphine were $\mathrm{HK} \$ 44.03$ and $\mathrm{HK} \$ 96.31$ respectively $(\mathrm{p}<0.0001)$.

Conclusion - When titrated according to patient's needs, IV ketorolac is more effective than IV morphine for analgesia after blunt limb injuries with activity but equally effective at rest. Ketorolac causes fewer adverse effects and is preferred by patients. When all costs are taken into account, ketorolac is less expensive to prescribe than morphine and should be considered as the dominant strategy of managing such pain in the emergency department.

Early recognition of myocardial damage: an emergency department based diagnostic test study

K R RICHELL HERREN, K MACKWAY-JONES, C R RICHARDS, C T SEREVIRATNE, $M$ W FRANCE, L COTTER

Department of Emergency Medicine, Manchester Royal Infirmary, Oxford Road, Manchester M13 9WL

Ruling out myocardial damage in patients with chest pain, traditionally requires a combination of serial electrocardiograms and enzymes. After 24 hours, this is sensitive enough in low risk cases to allow safe discharge (sensitivity $96 \%$ ). Moderate risk cases require admission for three days. Furthermore up to $8 \%$ of myocardial infarctions may be inadvertently discharged from the emergency department; $25 \%$ of these cases die.

Increasingly chest pain assessment units (CPAUs) are being utilised to identify patients with evidence of myocardial damage early. Proved safe in a prospective randomised controlled trial, no diagnostic test study with a blinded gold standard has studied the efficacy of the protocol in emergency department chest pain patients.

We studied 368 consecutive patients admitted to a chest pain assessment service at Manchester Royal Infirmary between 20 October 1997 and 30 October 1998. The service consisted of six hours of ST segment monitoring and CK-MB mass measurements (table 2). Troponin $\mathrm{T}$ measurements were also taken. Positive cases had ST segment changes or a CK mass of 5 or a change in two values of 3 . Positive cases were admitted.

Altogether 292 had a blinded gold standard, 13 withdrew form the study, and 63 did not return; 288 gold standards were a 48 hour troponin $\mathrm{T}$ and four WHO criteria. A positive troponin $\mathrm{T}$ was $0.1 \mathrm{ng} / \mathrm{l}$. CK-MB mass has suitable sensitivity in CPAU cases to exclude myocardial damage in the six hours (table 3).

Table 2 Timing of CK mass measurements

Duration of pain

\begin{tabular}{llll}
\hline Less than 3 hours & After 3 hours pain & After 6 hours pain & After 6 hours monitoring \\
More than 3 hours & On arrival & 3 Hours later &
\end{tabular}

Table 3 Comparison of CPAU protocol using $C K-M B$ mass and troponin $T$

\begin{tabular}{lll}
\hline & Sensitivity (\%) & Specificity (\%) \\
\hline CK-MB mass & 97.2 & 93 \\
Troponin T & 57 & 96.5 \\
\hline
\end{tabular}

Hidden structure revealed in ventricular fibrillation using a wavelet decomposition based analysis

G R CLEGG, P S ADDISON, J WATSON, M HOLZER, F R STERZ, C E ROBERTSON

Department of Accident and Emergency Medicine, Edinburgh Royal Infirmary, Lauriston Place, Edinburgh EH3 9YW

Objectives-To determine whether the surface electrocardiogram (ECG) recorded during ventricular fibrillation (VF) contains useful information about the state of the fibrillating myocardium using a novel continuous wavelet transform based analysis.

Methods - Thirty two digitised ECG traces of VF from an established porcine animal mode were analysed using a continuous wavelet transform method. This analysis technique is able to demonstrate dominant features within a signal, yielding a three dimensional plot showing feature energy, size, and temporal location. onstrated previously unreported structure. Distinct high energy bands were visible in the scalogram, with clear repeated temporal patterns. Some traces showed strikingly regula features during VF at the high frequency end of the scalogram

Conclusion - Ventricular tachyarrhythmias, VF in particular, are the leading cause of sudden cardiac death and are the focus of much atten tion. Until recently, the surface ECG recorded during VF was thought to represent disorganised and unstructured electrical activity of the heart. This new method of interrogating the ECG has shown a rich structure within the VF signal. We believe that wavelet transform methods could lead to the development of powerful tools for use in the resuscitation of patients with cardiac arrest, using this changing structure to reflect the changing state of the myocardium. Our work is not only of great potential importance in the future development of cardiopulmonary resuscitation in general, but also has implications for defibrillator manufacture.

Oral Presentation 1: Trauma/Shock, 4 December 1999

Plasma DNA as a marker for the early prediction of post-traumatic complications

T H RAINER, L Y S CHAN, N M HJELM, R A COCKS, Y M D LO

Accident and Emergency Medicine Academic Unit and Department of Chemical Pathology, Chinese University of Hong Kong and Prince of Wales Hospital, Hong Kong

Background and objective-Clinical research into therapies which may prevent or minimise post-traumatic complications is hampered by a lack of practical, highly sensitive, and
Results-The scalogram plots during VF dem- specific early predictors which allow targeting of high risk patients. The purpose of this study was to investigate the potential of cell-free (plasma) DNA, measured using real time quantitative polymerase chain reaction (PCR), as an early predictor of post-traumatic complications.

Methods-Ethical approval was obtained from the Chinese University of Hong Kong Research Ethics Committee to conduct observational research into the molecular response of patients to injury. Blood $(3 \mathrm{ml})$ was withdrawn from patients at a median time of 60 minutes (range 30-240; IQR 50-90) after injury, stored in heparinised tubes and analysed using real time PCR. PCR was used to quantify the amount of cell-free DNA in plasma and this was related to injury severity score (ISS), development of acute lung injury (ALI), organ failure (OF), and mortality.

Results-Median plasma DNA results from patients (median age 37 years, range 12-86; $83 \%$ male) and controls were as follows: control $(\mathrm{n}=30) 3154$ copies/ml, "minor" ( $\mathrm{n}=48$, ISS 1-14) 16311 copies/ml, major ( $\mathrm{n}=37$, ISS $\geqslant 16$ ) 181303 copies/ml (Kruskal-Wallis test $\mathrm{p}<0.0001$; a 58-fold increase between major and control values). In the major trauma group alone, median plasma DNA values in ALI-ve and ALI+ve subjects was 144563 copies/ml and 398225 copies $/ \mathrm{m}$ (Mann-Whitney test $\mathrm{p}<0.05$ ), in $\mathrm{OF}-\mathrm{ve}$ and $\mathrm{OF}+$ ve patients it was $54270 \mathrm{copies} / \mathrm{ml}$ and 326449 copies/ml (Mann-Whitney p<0.005), and for mortality it was $153101 \mathrm{copies} / \mathrm{ml}$ in those who survived and 315122 copies $/ \mathrm{ml}$ in those who died (Mann-Whitney $\mathrm{p}=0.17$ ). The area under the receiver operator characteristic curves for ALI was $0.88 \quad(95 \%$ confidence intervals (CI) 0.79 to 0.94 ), for OF was 0.89 (CI 0.80 to 0.95 ), and for mortality was 0.82 (CI 0.72 to 0.90 ). For ALI, plasma DNA values of >232 719 copies $/ \mathrm{ml}$ give a sensitivity of $100 \%$ (CI 100.0 to 100.0 ), a specificity of $81 \%$ (CI 70.6 to 89.0 ), and a positive likelihood ratio of 5.27. For OF, plasma DNA values of $>101615$ give a sensitivity of $95 \%$ (CI 75.1 to 99.2 ), a specificity of $81.5 \%$ (70.0 to 90.1 ), and a positive likelihood ratio of 5.15 .

Conclusion-Cell-free plasma DNA quantified using real time PCR may be used to predict within four hours of injury whether a patient is likely to develop post-traumatic organ failure and acute lung injury.

Influence of hypovolaemia on the pharmacokinetics and the electroencephalographic effect of propofol in the rat

PETER DE PAEPE ${ }^{\star}$, WIM DUTHOY ${ }^{\star}$, GERT VAN HOEY $^{\star \star}$, PAUL A BOON ${ }^{\star \star \star}$, FRANS M BELPAIRE ${ }^{\star}$,

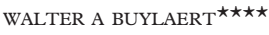

${ }^{\star}$ Heymans Institute of Pharmacology, ${ }^{\star \star}$ Department of Electronics and Information Systems, $\star \star \star$ Department of Neurology, $* \star * \star D e p a r t m e n t$ of Emergency Medicine, University of Ghent, Medical School, De Pintelaan 185, B-9000 Ghent, Belgium

Background - Pathophysiological changes during haemodynamic shock may alter the effect of different drugs by influencing the pharmacokinetics or by changing end organ sensitivity. No data are available for the anaesthetic propofol $(\mathrm{P})$ and in view of its frequent use in haemodynamically compromised patients the influence of hypovolaemia (removal of $30 \%$ of the blood volume) on the pharmacokinetics and pharmacodynamics of $\mathrm{P}$ in the rat was studied. 
Method-Chronically instrumented animals were randomly allocated to either the control $(\mathrm{n}=9)$ or the shock $(\mathrm{n}=9)$ group. In each group $\mathrm{P}$ was infused $(150 \mathrm{mg} / \mathrm{kg} / \mathrm{h})$ until isoelectric periods of $5 \mathrm{~s}$ or longer were observed in the electroencephalogram and blood concentrations were determined by HPLC. The changes in the electroencephalogram were quantified using aperiodic analysis in the $11.5-30 \mathrm{~Hz}$ frequency band, and used as a surrogate measure of hypnosis. The righting reflex was used as a clinical measure of hypnosis.

Results - The P dose needed to reach the electroencephalographic $5 \mathrm{~s}$ end point was $61 \%$ lower $(\mathrm{p}<0.01)$ in the shock animals compared with the control animals. A decrease in clearance $(-31 \% ; \mathrm{p}<0.01)$ and distribution volume $(-47 \% ; \mathrm{p}<0.01)$ of $\mathrm{P}$ was observed. To investigate end organ sensitivity, the electroencephalographic effect versus effect site concentration relation was determined using a hysteresis minimisation algorithm. This showed no changes in distribution of $\mathrm{P}$ to the brain and a $30 \%$ increased potency of $\mathrm{P}$ during haemorrhage. The concentration at the return of righting reflex was $24 \%(\mathrm{p}<0.01)$ lower in the shock animals.

Conclusion-An increased hypnotic effect of $\mathrm{P}$ occurred during hypovolaemia which can be explained by pharmacokinetic changes. However, an increase in central nervous system senstivity for $\mathrm{P}$ in shock animals may also contribute. Since we used whole blood concentrations to investigate the effect versus concentration relation, changes in protein binding of $\mathrm{P}$ in the shock animals cannot be excluded to account for the increased hypnotic effect.

A comparison of artificial intelligence techniques with UK TRISS for estimating Ps after trauma

DAVID C BECALICK, TIM J COATS

Academic Unit, Accident and Emergency Department, Royal London Hospital, Mile End Road, Whitechapel, London E1 1BB

Background-There are a number of scoring systems for predicting outcome after injury. The TRISS and APACHE systems have reasonable powers of discrimination, but poor congruity. This limits their application for individual patients. Non-linear modelling methods have the potential to increase understanding by highlighting complex relations between variables. It is hoped that a greater understanding of the factors influencing outcome after injury may assist in clinical management.

Method-A predictive model was constructed from the trauma database at the Royal London Hospital. An artificial neural network (ANN) used 16 pre-hospital collated variables: AIS scores, injury type, age, gender, systolic blood pressure, respiratory rate, GCS components, oxygen saturation, and heart rate. Raw inputs were used to eliminate the modelling employed in the ISS, RTS, and TRISS methods.

ANN connections were visualised using Hinton diagrams. This allowed a qualitative assessment of the relative importance of the input groupings in predicting outcome. A quantitative measure of input relevance used the squared weights per input over all input groupings expressed as a percentage ratio. This measure ranked head injury $(27.9 \%)$, age $(14.5 \%)$, chest injury (12.3\%), GCS voice $(8.5 \%)$, and AIS abdominal injury $(7.4 \%)$ as the most relevant outcome predictors. Visuali- sation by Kohonen self organising maps supported these estimates of predictor relevance and illustrated the decision surface projected onto two dimensions.

Results-The ANN discrimination by ROC curve $(0.921, \mathrm{p}<0.001)$ was significantly worse (SE 0.64, p<0.001) than the UK TRISS model $(0.941, \mathrm{p}<0.001)$ on the test set using the $\mathrm{z}$ statistic. The congruity was better for the ANN as measured by the Hosmer-Lemeshow (HL) statistic compared with the UK TRISS model (58.3/105.4, $\mathrm{p}<0.0001)$. The "goodness of fit" by the HI statistic was best at the higher end of the Ps distribution for both prediction methods. Weight inspection indicated that variables such as respiration rate and heart rate were almost redundant in predicting outcome.

\section{Trauma care in England and Wales 1989-97}

$M$ WOODFORD, D W YATES, F LECKY ON BEHALF OF THE TRAUMA AUDIT AND RESEARCH NETWORK

Trauma Audit and Research Network, Clinical Sciences Building, Hope Hospital, Eccles Old Road, Salford M6 8HD

The decline in the number of deaths attributable to trauma over the past 20 years has been linked to improvements in road engineering, seat belt and helmet laws, alcohol control and safety initiatives in the workplace. These primary and secondary prevention initiatives are undoubtedly important but it is also to be expected that "post-impact care" by the health service will have had an additional effect on survival. Unfortunately effective clinical management is not always achieved. In 1988, a report published by the Royal College of Surgeons of England drew attention to inadequacies in the management of patients with majo injuries. A number of initiatives were proposed including the development of audit programmes to measure the effectiveness of any changes.

This paper examines the records of patients who were admitted to hospitals which return data to the Trauma Audit and Research Network. At the end of 1997 there were 91602 patients on the database from 99 hospitals in England. Twenty hospitals have contributed continuously since 1989 .

Outcome analysis shows that there has been a gradual decline in the odds ratio of death over the period examined so that for 1993 and subsequent years there is a significant reduction compared with the baseline year of 1989

Process analysis shows that there has been a trend to an increasing frequency of specialis registrar and consultant involvement in the management of more seriously injured patients with a corresponding decline in the frequency of senior house officer as the first doctor seeing such patients.

Hospital performance is compared using the standardised $\mathrm{W}$ statistic and $95 \%$ confidence intervals. Wide variations can be seen in the number of additional survivors per 100 patients treated.

The results show a clear improvement in outcome for trauma patients in England and Wales over the last 10 years which cannot be attributed to changes in frequency or severity of the injuries. There remains however significant variation between hospitals and this would suggest there is potential for further improvement.
Effect of traumatic brain injury on the biphasic response to haemorrhage

G MCMAHON, E KIRKMAN ${ }^{\star}$, R LITTLE

MRC Trauma Unit, Stopford Building, University of Manchester, School of Biological Sciences and ${ }^{\star}$ University of Durham

Objective-To evaluate the effect of traumatic brain injury on progressive simple haemorrhage of $40 \%$

Methods-The study was conducted using 24 male Wistar rats $(240-260 \mathrm{~g})$ anaesthetised with alphadolone/alphaxolone. Instantaneous heart rate was calculated from R-R intervals from the electrocardiogram, and mean arterial pressure via a cannula in the tail artery. Normal body temperature was maintained throughout.

Three groups of eight animals were studied. The first group received a moderate brain injury (1.6-1.8 atm pressure, $10 \mathrm{~ms}$ duration applied directly onto the dura over the parieta lobe via a cannula fixed to the skull); the second group received a mild injury (1.0-1.2, 10 $\mathrm{ms}$ ), while the third underwent all the surgery but not the percussion injury. Ten minutes after head injury the animals underwent progressive simple haemorrhage from their tail vein at the rate of $2 \%$ blood volume per minute until $40 \%$ haemorrhage was achieved. Physiological parameters were stored on a computerised data acquisition system.

Results-Moderate traumatic brain injury caused an attenuation of the normal bradycardic phase of the response to simple haemorrhage. The heart rate and blood pressure remained higher for longer. This difference became statistically significant at $25 \%$ of haemorrhage $(p<0.05)$ and continued to $40 \%$ haemorrhage $(\mathrm{p}<0.01)$. Mortality increased to $50 \%$ by time 45 min after injury in this group. Mild brain injury caused no significant effect on the biphasic response. The control group demonstrated the normal biphasic response. There were no mortalities in either the mild injury or control group during the study period.

Conclusion-This work demonstrates a modification of the normal homoeostatic response of progressive simple haemorrhage by the coexistence of moderate traumatic brain injury. Secondary brain insults are known to be associated with a very significant increase in mortality after head injury. These results suggest the possibility the brain injury itself contributing to secondary insults by its effect on responses to peripheral injury, adding weight to the hypothesis of a bidirectional interaction between peripheral injuries and traumatic brain injury.

Oral Presentation 2: Diagnostic Testing, 4 December 1999

Convergent validity of the Manchester pain scale

FIONA LYONS, RUSSELL BOYD, KEVIN MACKWAYJONES

Department of Emergency Medicine, Hope Hospital, Salford, Manchester M6 8HD

Objective-To test the convergent validity of the Manchester pain scale when compared with the current "gold standard" in children's pain assessment-the Oucher pain scale. Methods-152 children presenting to the emergency department with pain had pain scale assessments according to both the Manchester pain scale and the Oucher scale. The order of presentation of the scales was randomised. The degree of convergence 
between the scales was assessed using Spearman's rank correlation as well as Bland and Altman plots.

Results-113 children used the numerical scales; the correlation coefficient for the scales was 0.802 . Thirty nine children used the pictorial scales; the correlation coefficient was 0.820 for these scales.

Discussion - There is strong convergent validity between the scales as shown by a high degree of correlation between the numerical and pictorial scores generated by the Manchester pain scale and the Oucher scale.

Conclusion-The Manchester pain scale can be used to assess pain in children presenting to emergency departments.

Right first time: use of an aluminium filter to improve visualisation of the cervicothoracic junction on the lateral $x$ ray of the cervical spine

A MACNAMARA ${ }^{\star}$, A HOBART ${ }^{\star}$, S STEVENS ${ }^{\star \star}$, J REYNOLDS ${ }^{\star \star}, \mathrm{P}_{\mathrm{CROWE}}{ }^{\star \star}$

${ }^{\star}$ Department of Accident and Emergency Medicine, and ${ }^{\star *}$ Department of Radiology, Birmingham Heartlands Hospital, Bordesley Green East, Birmingham

Background -Initial imaging of the cervical spine in the trauma victim consists of a plain $x$ ray cervical spine series. The lateral radiograph is the most useful single projection, demonstrating $70 \%$ of bony injuries. The $\mathrm{C} 7 / \mathrm{T} 1$ junction is often poorly demonstrated owing to overlying shoulder musculature, which results in difficulty or failure to visualise this area. We have developed a technique combining a filter and high $\mathrm{K}-\mathrm{V}$ technique to improve visualisation of the cervicothoracic junction on the lateral cervical spine $x$ ray. Objective-To determine whether the rate of visualisation of $\mathrm{C} 7 / \mathrm{T} 1$ can be improved by the use of an aluminium filter and a high K-V technique on the lateral cervical spine $x$ ray.

Method-An aluminium filter was constructed, and tested with a tissue phantom to assess the optimum exposure settings. A prospective randomised controlled trial was undertaken on consenting patients requiring cervical spine $x$ rays after trauma. The resulting $x$ rays were assessed blindly by two consultant radiologists. The primary measurement was visualisation of the upper border of T1. Other aspects of image adequacy were also assessed.

Results-180 patients were recruited to the study. The groups were comparable for age and sex. There was a statistically significant increase in the rate of visualisation of the C7/T1 junction when using the filter $\left(\chi^{2}\right.$ test, $\mathrm{p}=0.001)$. This increase was $32 \%(95 \%$ CI 15.4 to $48.6 \%$ ). Overall image adequacy was not compromised and visualisation of spinous processes and facet joints also improved.

Conclusion-Use of an aluminium filter and a high $\mathrm{K}-\mathrm{V}$ technique greatly increases the rate of visualisation of $\mathrm{C} 7 / \mathrm{T} 1$ on the lateral cervical spine $x$ ray. The implications of this technique are presented.

\section{ROMEO: evaluation of a "rapid rule out"} chest pain pathway

CLARE TAYLOR, STEPHEN MEEK, DAVID WATSON

Emergency Department, Royal United Hospital, Bath BA1 3NG

Aims - To evaluate the first three months' use of the emergency department "ROMEO" (rule out myocardial events on obs ward) pathway for "low risk" patients with chest pain.
Methods - This pathway combines serum troponin I levels (on arrival and 12 hours after onset of pain) and serial electrocardiogram (ECGs) to exclude myocardial damage. Subsequent pre-discharge exercise tolerance test (ETT), currently performed by the cardiology department, excludes simple angina.

The first 59 ROMEO patients, from 19 April to 16 July 1999, were reviewed using prospectively collected data.

Results - The results were as follows:

- 6 raised initial troponin; not further managed on the pathway.

- 35 acute myocardial infarction (AMI) and angina excluded.

- $9 \mathrm{AMI} /$ high risk unstable angina excluded, no pre-discharge ETT.

3 AMI excluded, but positive ETT.

- 6 referred on for admission: one raised 12 hour troponin I, 4 developed ECG changes, 1 suffered continuing pain.

Thus 46/59 (78\%) had myocardial damage excluded, were stratified as low risk for future cardiac events and discharged. 35/59 (59\%) also had stable angina excluded by ETT.

Timing of ETT after negative 12 hour troponin $(\mathrm{n}=47)$ :

- 24 at 0-4 hours, 3 unrecorded

7 at 4-8 hours, 7 discharged, delayed ETT as OP

- 4 at 8-60 hours, 2 physically unable

Mean observation unit stay 17 hours (range

$2-60$ ). Only $65 \%$ of patients were discharged within 20 hours.

30 day follow up:

- 18/32 eligible patients contacted by telephone.

- 14/18 had no further pain, attendances, or GP consultations.

- Required further GP investigation or treatment.

- Readmitted with chest pain.

Conclusions-Initial results suggest the ROMEO pathway is safe and effective but sig nificant delays in obtaining ETT are delaying discharge and need addressing.

Comparison of radiography and magnetic resonance imaging in the detection of injuries after paediatric elbow trauma T H RAINER, J F GRIFFITH, D J ROEBUCK, J C Y CHENG, C METREWELI

Accident and Emergency Medicine Academic Unit, Chinese University of Hong Kong and Prince of Wales Hospital, Hong Kong

Background-Paediatric elbow injuries may not be detected by plain radiography and the type and extent of injuries, which may be overlooked, is unknown. This study investigates the extent of bone, cartilaginous, or soft tissue injury detected by magnetic resonance imaging (MRI), that may go undetected when radiographs are used to assess paediatric elbow trauma.

Methods - Fifty children (mean age 7.3 , range 2-12 years; 32 male) presenting to the emergency department of a teaching hospital after elbow trauma requiring radiography and referred for orthopaedic follow up were imaged with MRI. Radiographs and MR images were assessed for the presence and extent of definite fractures, effusions, bone bruising, muscle and ligamentous injury. Any alteration in management following MRI was also recorded. The average time from injury to MRI was 6 days (range 1-18 days). All radiology examinations were reported with consensus by two experienced radiologists.

Results-The following abnormalities were found in the 50 children with radiography compared with MRI respectively: normal (8v 0 ), effusion (16 v18), equivocal fracture ( $6 v$ $1)$, definite fracture $(20 v 31)$. MRI showed unsuspected physeal injury in four of the 50 , articular cartilage injury in three, unsuspected bone bruising in 32 , muscle injury in 18 , and ligamentous injury in four patients. In the 16 patients with an effusion only on radiographs, MRI showed a fracture in seven, bone bruising in four, muscle oedema in three, and an effusion in two. In the eight patients with normal radiographs, MRI showed a fracture in one, bone bruising in two, ligamentous injury in two, and effusions in three. However, these additional findings did not alter management.

Conclusion-In children with elbow trauma, MRI revealed 55\% more definite fractures than radiographs and $14 \%$ more unsuspected physeal plate or articular cartilage injuries. In this study the majority of children with normal radiographs and all of those with a radiographic effusion had sustained an appreciable bone or soft injury.

\section{Posters: Miscellaneous}

Accidental hypothermia: the effects of rewarming on plasma $\mathbf{p H}$, ionised calcium, ionised magnesium, and serum parathyroid hormone

J J MCINERNEY, A B BREAKELL, W MADIRA, T DAVIES, P A EVANS

Department of Accident and Emergency, Leicester Royal Infirmary, Infirmary Close, Leicester LE1 $5 W W$

Background - In accidental hypothermia (core temperature $<35^{\circ} \mathrm{C}$ ) the underlying physiological mechanisms responsible for high morbidity and mortality remain obscure. Changes in plasma calcium and magnesium concentrations have been reported in other forms of tissue injury and are associated with poor outcome; this study investigated the changes in these ions, $\mathrm{pH}$, and PTH during rewarming

Methods-Eight patients (four men, four women) aged 45 to 85 years (mean age 74.3 ), admitted with accidental hypothermia were included in the study. Patients were rewarmed with dry warm blankets and fluid replaced by crystalloid at $40^{\circ} \mathrm{C}$. Blood for ionised calcium and magnesium, $\mathrm{pH}$, and $\mathrm{PTH}$ was collected at presentation, during rewarming, and at 24 hours.

Results-Four patients were admitted with mild $\left(32-35^{\circ} \mathrm{C}\right)$ and four with moderate $(28$ $32^{\circ} \mathrm{C}$ ) hypothermia. All patients responded to rewarming, with the initial mean rate rise in core temperature $0.78^{\circ} \mathrm{C} / \mathrm{h}$. Rewarming to $32^{\circ} \mathrm{C}$ had no significant effect on the presenting acidosis $(\mathrm{p}=0.1740)$; above $32^{\circ} \mathrm{C} \mathrm{pH}$ increased with temperature $(\mathrm{p}<0.0001)$. There was a negative correlation between $\mathrm{pH}$ and both ionised calcium $(\mathrm{p}=0.0005)$ and magnesium $(p=0.0488)$ below $32^{\circ} \mathrm{C}$. Above this temperature the relation was significant only for calcium $(p=0.0494)$. PTH and ionised calcium correlated positively $(p=0.0041)$ and negatively $(p=0.0039)$ in moderate and mild hypothermia respectively. Conclusion-During rewarming changes in $\mathrm{pH}$ are associated with changes in ionised calcium and magnesium. Poor outcome-that is, survival $<7$ days, was associated with age $(\geqslant 84$ years), presentation temperature $\left(<32^{\circ} \mathrm{C}\right)$, and non-physiological correlation between PTH and ionised calcium. More data are required to consolidate and confirm these findings. 
Corneal donation within the accident and emergency department

JASON LONG, DAVID RITCHIE, DIERDRIE WALSH, FIONA RUSSELL

Accident and Emergency Department, Victoria Infirmary, Glasgow G42 9TY

Objective-To increase corneal donation from patients who die within the A\&E department. Design - Observational study over a four month period of an active policy to request consent for corneal donation from relatives of patients dying within the A\&E department. Exclusion criteria were patients $<16$ years, death in suspicious circumstances, patients who on presentation to the A\&E department had a known contraindication to corneal donation, and those patients whose relatives were not present in $\mathrm{A} \& \mathrm{E}$ during the 12 hour retrieval period. Following the request by staff, relatives were surveyed at the time about their attitudes to corneal donation within the A\&E department.

Setting-Inner city A\&E department seeing approximately 75000 patients per year located in the west of Scotland; population 2.8 million with 20 acute hospitals with number of deaths in A\&E annually.

Results-During the four month period there were 47 deaths, of which 11 were excluded. In addition 11 were missed from the study. Of the remaining 25 patients, nine gave consent, none were then found to have a contraindication, and nine pairs of corneas were retrieved. In the study four out of 24 carried a donor card or expressed a wish and only three out of nine patients who donated corneas carried donor cards. From the survey of relatives, 21 of 24 thought it was appropriate to be approached regarding corneal donation at the time of a sudden death in the A\&E department and one of 24 were distressed by this request.

Conclusion-In January 1999 the Manchester Eye Bank was unable to issue any corneas for grafting. In 1998 there were 28 pairs of corneas retrieved in the west of Scotland, 16 from ITU patients, only one pair from this $\mathrm{A} \& \mathrm{E}$ department, and two in total from A\&E departments in the west of Scotland. Projecting our results forward for one year we would expect to increase by $100 \%$ the number of corneas donated in the whole of the west of Scotland simply by implementing this policy in one $\mathrm{A} \& \mathrm{E}$ department. A\&E is clearly a specialty which can help to address the national shortage of donor corneal tissue.

Chemical incident surveillance and accident and emergency departments

VIRGINIA MURRAY, ALISON JONES, EURIPIDES ERIPIDOU

Chemical Incident Response Service, Medical Toxicology Unit, Guy's and St Thomas's Hospital Trust, Avonley Road, London SE14 5ER

Background-Since 1996 the Chemical Incident Response Service (CIRS) has been contracted to health authorities in six of the eight English regions. It provides 24 hour information and advice on the management of chemical incidents and works closely with the other facilities at the Medical Toxicology Unit-namely, the National Poisons Information Service (London), clinicians, and the toxicology laboratory. Since its establishment in 1995 CIRS has provided surveillance of chemical incidents for health authorities. In addition, data are recorded by the accident and emergency department (A\&E) contacting the unit. This allows CIRS to identify the chemical associated with the incident and enables A\&E to have an external record of the events in which they are involved. From CIRS experience, concern exists about the trainin and resources available within A\&Es for effective response to minimise the impact of these events. New guidance on planning for major incidents by the NHS executive was published in November 1998 and section 5 applies to the acute hospital and its A\&E. Using surveillance, CIRS is trying to determine the impact of this on $\mathrm{A} \& \mathrm{E}$ response to chemical incidents and contamination.

Results-The number of chemical incident reported to CIRS rose from 474 in 1995 to 917 in 1998, with 603 reported by August 1999. Data on A\&Es by frequency and type of chemical incident show regional variation and will be presented. So far in 1999, healthcare facilities have been identified as being affected by $31(5 \%)$ chemical incidents. By describing three recent incidents vulnerable areas in training and resources within A\&Es will be demonstrated.

Conclusions-The monitoring and surveillance of chemical incidents allows for the identification of and research into events which might otherwise not have been collated. In addition, the surveillance programme has identified the need for established and validated procedure that may be used in the event of a chemical incident resulting in contamination of $\mathrm{A} \& \mathrm{E}$ and healthcare facilities.

\section{Autokabalesis in south east Scotland} C GRAHAM, J P BEALE, J P WYATT, D BEARD, A BUSUTTIL

Scottish Trauma Audit Group, Forensic Medicine Unit in the University of Edinburgh and Acciden and Emergency Department of the Royal Infirmary of Edinburgh

Introduction and aim-Committing suicide by jumping from a height has been termed "autokabalesis". This study investigates its epidemiology.

Method - Information on suicidal high falls in south east Scotland was gathered over seven years (1992-98) from data collected prospectively by the Forensic Medicine Unit of Edinburgh University and the Scottish Trauma Audit Group. Further data were obtained from police investigations and autopsies, which were performed in all cases. Injuries sustained were scored according to the abbreviated injury scale (AIS), 1990 revision, generating injury severity scores (ISS)

Results - Sixty three individuals (50 males, 13 females) appeared to have committed suicide by jumping or falling from a height. The background to the suicides was diverse, but 44 individuals $(70 \%)$ had been previously treated for psychiatric illness, 18 having previously attempted suicide. The majority of those who died were aged less than 40 years. The most common site for suicidal high falls was from high bridges, with two bridges (each more than $25 \mathrm{~m}$ high) accounting for 23 deaths $(37 \%)$. Fifty two individuals were found dead at the scene, two died at the scene after being found alive, and nine $(14 \%)$ reached hospital alive. ISS range was $16-75$, with 22 individuals having scores of 75 . These individuals had a total of 24 injuries acknowledged to be unsurvivable (AIS = 6), comprising 10 thoracic aortic ruptures, eight massive brain brainstem injuries, four cardiac injuries, two high spinal cord transections.

Conclusions-Autokabalesis represents a small subgroup, with characteristics which diffe from other fatal high falls. The high rate of pre-hospital death reflects both the height of the fall (and the consequent major injuries) and the site/timing of the fall. Prevention of suicide is acknowledged to be difficult to achieve and certainly the results suggest that hospital treatment of injuries sustained has little to offer in terms of reducing the death rate from suicidal high falls.

Cycling safety: injury prevention in Oxford cyclists

LAWRENCE MCGUIRE, NICOLA SMITH

210 Headington Road, Oxford OX3 7PS

Aim-To assess injury prevention measures in cyclists in Oxford.

Method-A prospective observational survey of a series of cyclists passing a single point on a busy city road in reduced lighting. Two observers jointly recorded four measures of injury prevention in subjects: use of front or rear light, high visibility clothing, and cycling helmet. Incidences of the other interventions were analysed in relation to helmet use/nonuse.

Results-A total of 392 cyclists were observed over one hour. Fourteen had all four measures observed, while 137 (34.9\%) had none. Frequencies of interventions observed were: lit front light 190, lit rear light 197, both light lit 163, helmet used 104(26.5\%), and high visibility clothing 39 .

Despite the helmet using group's smaller size, it contained a higher proportion of cyclists with lit front light $(60.6 \% v 44.1 \%)$, lit rear light $(61.5 \% v 46.2 \%)$, and high visibility clothing $(27.9 \%$ v $3.5 \%)$, than the non-helmet using group. Whereas only $22 \%$ of the helmet users had no other observed measures, $47.2 \%$ of non-users did so.

Conclusion-Cycling helmet use was observed to be related to the use of other collision prevention strategies in conditions of reduced visibility. Reasons for this may include higher levels of risk awareness and knowledge of safe cycling practices in the smaller helmet using group. However, current measures by cyclists in a major cycling centre may be insufficient to prevent collisions and consequent serious injury or death.

\section{Posters: Training/IT}

Learning practices of specialist registrars in accident and emergency medicine

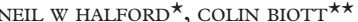

*Accident and Emergency Department, Queen Elizabeth Hospital, Sheriff Hill, Gateshead, Tyne E Wear NE9 6SX, and **Department of Educational Studies, University of Northumbria at Newcastle, Coach Lane Campus, Benton, Newcastle upon Tyne NE7 7XA

Introduction-In recent years training programmes for specialist registrars (SpRs) have been developed. Few data are available to understand how an individual $\mathrm{SpR}$ learns and whether the knowledge they assimilate during training is directly relevant to their final consultant role. To understand training it is first important to understand how an $\mathrm{SpR}$ learns.

Aims - (1) To identify methods of knowledge acquisition and usage of $\mathrm{SpRs}$ in $\mathrm{A} \& \mathrm{E}$ medicine. (2) To understand the learning processes that are occurring within this higher specialist training period. (3) To gain insight into factors that directly influence the learning processes of these doctors.

Methods - A sample of five newly appointed consultants and the five most junior SpRs in the northern deanery participated. During a 
three month period at the start of 1999 a series of semistructured interviews were performed, which were followed by a group discussion to develop themes and ideas. Interview transcripts were analysed to generate concepts and theories about the nature of learning that was being used and the factors that affected it.

Results-From the qualitative data a number of key themes were developed. The methods of knowledge identification and the nature of the knowledge identified by SpRs were clearly described and were compared with the learning practices of consultants newly into post. Factors that affected learning, such as an individual's role, their mental state, time constraints, and agendas/curricular, were clarified. An improved understanding of responsibility and the control of the individual's learning were also described.

Conclusions - The implications drawn are significant for both the trainee's learning and the future development of training programmes and trainers, such as increasing emphasis on the adaptation of training to meet an individual's learning needs. Recommendations are made about the relation between trainer and trainee and also the relation between $\mathrm{SpR}$ training and the newly appointed consultant's role. The dilemma between service commitment and training of an $\mathrm{SpR}$ is also highlighted.

Motivations for a career in accident and emergency medicine: profile and attitudes of candidates interviewed for specialist registrar posts in 1999

H D M PONCIA, J RYAN

Department of Accident and Emergency Medicine, Royal Sussex County Hospital, Brighton $B N 2$ 5BE

Objectives - To assess the profile and motivating factors of junior doctors interviewed for specialist registrar ( $\mathrm{SpR})$ posts in accident and emergency (A\&E) medicine in the United Kingdom.

Methods-A multiregional questionnaire study was conducted. An anonymous questionnaire was given to candidates interviewed for $\mathrm{SpR}$ posts in A\&E medicine. Data collected included age, sex, year of graduation, and postgraduate degree. Candidates responded to 24 questions about their motivations for choosing $\mathrm{A} \& \mathrm{E}$ medicine as a career. Responses were marked on a $10 \mathrm{~cm}$ visual analogue scale.

Results-Eight regions participated in the study. Forty seven (90\%) questionnaires were returned over a six month period; 35 (74\%) respondents were male and $11(23 \%)$ were female (one respondent did not answer). Candidates had a median age of 31.5 years (mean 32.1; range 26-42; SD 3.6). Candidates had completed a median of 7.5 years since graduation (mean 9.2; range 4-18); 27 (59\%) had FRCS/MRCS or FRCSI, eight (17\%) had MRCP, seven (15\%) had FRCS (A\&E). If the median was used as the most representative parameter, the factors in choosing emergency medicine as a career in decreasing order of importance were: (1) Emphasis on acute care (median (M) 88; mean (m) 87.5). (2) Working as part of a team $(M=86 ; \mathrm{m}=82)$. (3) Performing practical procedures $(M=86$; $\mathrm{m}=82)$. (4) Contact with patients $(M=86$; $\mathrm{m}=80.5)$. (5) Experiences of $\mathrm{A} \& \mathrm{E}$ as an $\mathrm{SHO}$ $(M=84 ; m=80.2)$. (6) Diversity of clinical pathology $(M=83 ; m=77.5)$. (7) Opportunity to be involved in teaching $(M=80 ; \mathrm{m}=75.6)$. (8) Opportunities to obtain a consultant post
$(M=79 ; m=71.4)$. (9) The structure of $\mathrm{SpR}$ training in $A \& E(M=74 ; m=60.4)$. (10) The influence of an $\mathrm{A} \& \mathrm{E}$ adviser or mento $(M=69 ; m=7.6)$. (11) Experiences as a medical student ( $M=64 ; m=57.3)$. (12). Opportunities to obtain a registrar post $(M=63$, $\mathrm{m}=60.4)$. (13) Opportunity for research $(M=57 ; m=60.4)$. (14) Flexibility in choosing or changing practice location $(M=50$ $\mathrm{m}=48.7)$. (15) Change in career direction $(M=50 ; m=4.4)$. (16) Opportunity to work shifts $(M=49 ; m=45.5)$. (17) Negative experiences working in another specialty $(M=49$ $\mathrm{m}=43.4)$. (18) Work and travel overseas $(M=49 ; m=28)$. (19) Less involvement with the continuity of care of patients $(M=46$; $\mathrm{m}=48.6)$. (20) Length of specialist registra training $(M=42 ; m=39)$. (21) Opportunity to work flexibly as a consultant $(\mathrm{M}=36$ $\mathrm{m}=39.3)$. (22) Financial gain $(M=30$; $\mathrm{m}=34.2)$. (23) Opportunity to train flexibly as a registrar $(M=17 ; m=27)$. (24) Exposure to emergency medicine on television $(M=15$; $\mathrm{m}=28.5$ ).

Conclusions-Most shortlisted candidates were male and surgically trained. The most important factors influencing candidates' decisions to pursue a career in emergency medicine were the emphasis on acute care, working as part of a team, performing practical procedures, contact with patients, the diversity of clinical pathology, and the opportunity to teach. Applicants choose emergency medicine largely owing to clinical factors but are also significantly influenced by experiences as an $\mathrm{SHO}$ or as a student, the structure of $\mathrm{SpR}$ training, and career opportunities.

Senior house officers in accident and emergency-the learning curve M SAKR, J ANGUS, J PERRIN, C NIXON, J NICHOLL, J WARDROPE

Accident and Emergency Department, Northern General Hospital, Herries Road, Sheffield S5 $7 A U$

Introduction-Senior house officers (SHOs) spend six months in the A\&E department. Training in most departments includes induction course and weekly teaching sessions. Training concentrates mainly on life threaten ing conditions and multiple trauma patients. There is some training on the more common "minor injuries". As a part of a majo randomised study examining the managemen of minor injuries we measured the performance of our SHOs in the treatment of mino injuries in the first three months of their attachment and compared it with the last three months.

Patients - A total of 749 patients over the age of 16 presenting with minor injuries to the A\&E department were studied.

Setting - A large urban teaching hospital A\&E department.

Design - A part of a randomised controlled study examining the care provided to minor injuries patients by SHOs and nurse practitioners. Patients were assessed first by the SHO then by experienced research fellow independently. At a later stage comparison of both assessments and management were compared.

Main end points-Comparison of error rates between the first three months and the last three months.

Results-There was significant reduction in clinical error rates in the last three months ( $\mathrm{p}$ $=0.012$ ), also an apparent reduction in radiological error rates but this was not statistically significant $(\mathrm{p}=0.11)$; see table 4 .
Table 4 SHOs'learning curve

\begin{tabular}{lll}
\hline & $\begin{array}{l}\text { First 3 } \\
\text { months }\end{array}$ & $\begin{array}{l}\text { Last 3 } \\
\text { months }\end{array}$ \\
\hline Total seen & 406 & 343 \\
Referred & 37 & 25 \\
Errors in history & 3 & 1 \\
Errors in past history & 9 & 2 \\
Errors in examination & 13 & 7 \\
Errors in treatment & 29 & 15 \\
Errors in follow up & 22 & 13 \\
$x$ Ray requesting & & \\
$\quad$ Sign more & 57 & 39 \\
$\quad$ Sign less & 21 & 12 \\
$\quad$ Inadequate & 3 & 2 \\
$x$ Ray interpretation & & \\
$\quad$ Sign false negative & 4 & 2 \\
$\quad$ Sign false positive & 5 & 5 \\
\hline
\end{tabular}

Posters: Pre-hospital Care

Communication at the pre-hospital/ accident and emergency interface: a case of 'Don't quote me, that's what you heard, not what I said"

J J MCINERNEY, C WARD, T HASSAN, D QUINTON

Department of Accident and Emergency, Leicester Royal Infirmary, Infirmary Close, Leicester LE1 $5 W W$

Introduction-Information about the imminent arrival of critically ill patients is relayed by ambulance control to some A\&E departments, allowing timely and adequate preparation of staff. However, anecdotal evidence suggests that this lengthy communication chain may mimic the game of Chinese whispers, by diluting factual accuracy.

Methods-Consecutive emergency call sheet (ECS) messages received from ambulance control were collected prospectively over two months. Pre-hospital patient report form (PRF) were compared with ECS and A\&E notes to determine adequacy of transfer of demographic and physiological data. A prehospital questionnaire was posted to all 57 regional ambulance service headquarters in the United Kingdom inquiring about their current system of communicating pre-hospital information to A\&E departments.

Results-142 consecutive ECS and 90 associated PRF were collected. Accurate documentation of demographic and physiological data was achieved in 36/142 ECS (95\% confidence interval (CI) 18.43 to 33.33) compared with 70/90 PRF (95\% CI 67.79 to 85.87 ), when compared with A\&E notes. PRF notation of physiological parameters, such as respiratory rate $(60 / 68 ; 95 \%$ CI 78.13 to 94.78$)$, perfusion $(48 / 68 ; 95 \%$ CI 58.29 to 81.02$)$, and GCS $(63 / 68 ; 95 \%$ CI 83.67 to 97.57$)$, was high. Transfer of these parameters to corresponding ECS was poor; respiratory rate $(32 / 68 ; 95 \%$ CI 34.83 to 59.55$)$, perfusion $(26 / 68 ; 95 \%$ CI 26.71 to 50.82$)$, and GCS (35/68; $95 \%$ CI 39.03 to 63.78$)$.

Thirty eight questionnaires were collected ( $67 \%$ response rate). Twenty regions communicated to $\mathrm{A} \& \mathrm{E}$ departments via ambulance control-16 by both direct radio link ambulance control, and two by radio link only. Twenty seven regions relayed some form of pre-hospital triage score by these communication methods.

Conclusions-This study shows that prehospital communication to $\mathrm{A} \& \mathrm{E}$ via ambulance control, which is a common practice nationally, results in inferior information transfer. Conjunction of a national prehospital triage scoring system with a direct communication link may prevent this information wastage. 
A survey of the perceived quality of patient handover by ambulance staff in the resuscitation room

SHOBHAN THAKORE, WILLIAM MORRISON

Accident and Emergency Department, Ninewells Hospital, Dundee DD1 $9 S Y$

Aim-This study aimed at examining the quality of handover of patients in the resuscitation room by describing the current perceptions of medical and ambulance staff

Methods-A descriptive survey using two anonymous questionnaires to gauge current opinion. The first was designed for medical staff to complete and the second for ambulance staff. Questionnaires were distributed to medical staff in two teaching hospital A\&E departments, seeing a combined total of over 120000 new patients per annum. They were also distributed to ambulance personnel in the Tayside region of Scotland.

Results - 30 medical and 67 ambulance staff completed questionnaires. $33 \%$ of medical staff felt they were able to give feedback on the management of patients en route to hospital and $23 \%$ felt able to give feedback on the handover received. $19.4 \%$ of ambulance staff received formal training in giving a handover, $83 \%$ of the others felt there was a need for training.

Medical staff conveyed their belief that handovers were very variable between crews and that they did not feel radio reports were well structured. Ambulance crews felt they provided well structured radio reports, but felt that medical staff did not pay attention to their handovers.

Ambulance and medical staff felt handovers were good, though medical staff were less positive about handovers dealing with self poisoning and chest pain. Both appear to be least confident with the handover of paediatric emergencies. Medical staff were generally less satisfied with the reporting of vital signs than the history provided.

Conclusions - The perception of the patient handover is generally positive, but there may be some room for improvement in ambulance staff training. Such training should be based around a system recognisable to medical staff whereby patient details are followed by a concise history of the events, general medical condition, and salient physical and vital signs. Medical staff will thereby possibly pay more attention. The aim being a smooth and efficient transfer from pre-hospital agencies to A\&E staff.

Pre-hospital anaesthesia by emergency physicians: is it safe?

C A MACKAY, J TERRIS, T J COATS

Helicopter Emergency Medical Service, Royal London Hospital, London E1 1BB

Objectives-To determine if there were differences in practice or intubation mishap rate between anaesthetists and $\mathrm{A} \& \mathrm{E}$ physicians performing rapid sequence induction of anaesthesia (RSI) in the pre-hospital setting.

Methods - All patients who underwent RSI by a Helicopter Emergency Medical Service doctor from 1 March 1997 to 30 April 1999 were studied by retrospective analysis of in-flight run sheets. Time to anaesthesia was recorded from the time of arrival on scene to the time of intubation. Intubation mishaps were classified as repeat attempts at intubation, repeat drug administration, arrhythmia, and failed intubation.

Results-RSI was performed on 359 patients by 10 anaesthetists and nine emergency physicians. Time to anaesthesia was similar in both groups $(\mathrm{p}=0.59)$. Emergency physicians recorded a larger number of patients as having Cormack and Lehane grade 3 or 4 laryngoscopy than anaesthetists $(\mathrm{p}<0.0001)$ and were more likely to use a gum elastic bougie to assist intubation $(p=0.024)$. Patients treated by emergency physicians did not have a significantly different pulse, blood pressure, oxygen saturation, or end tidal carbon dioxide to patients treated by anaesthetists at any time after intubation. Emergency physicians were more likely to anaesthetise patients with a Glasgow coma score $>12$ than anaesthetists $(p$ $=0.003)$. There were two failed intubations $(1 \%)$ in the anaesthetist group and four $(2.5 \%)$ in the emergency physician group Repeat attempts at intubation and repeat drug administration occurred in $<2 \%$ of patients in each group. Only two patients experienced any arrhythmia (both in anaesthetist group). Conclusions-RSI performed by emergency physicians was not associated with a highe failure rate or an increased number of intubation mishaps than RSI performed by anaesthetists. Emergency physicians were able to safely administer sedative and neuromuscular blocking drugs in the pre-hospital setting. We suggest RSI can be safely performed by appropriately trained emergency physicians.

\section{Calls to 999 ambulance services priori-} tised as non-urgent: who calls and why

JEREMY DALE, SUSAN WILLIAMS, THERESA GODDEN, JO HIGGINS, EDWARD GLUCKSMAN, HELEN SNOOKS, CHRIS HARTLEY-SHARPE, ROBERT CROUCH, RICHARD HOOPER

clo Dr Susan Williams, Department of General Practice and Primary Care, GKT Medical School, 10 Cutcombe Road, London SE5 9Rf

Introduction - With research evidence showing repeatedly that a significant minority of 999 callers do not need urgent clinical care, the Department of Health has considered the establishment of a "category C" for patients in neither life threatening nor serious condition, to which ambulance services could plan local responses with purchasers. The same response time standards currently apply to these calls as more serious ones, but may not in the future. Priority despatch systems allow for the triage of calls according to level of urgency. We present demographic and medical information on a sample of non-urgent calls to the London Ambulance Service between April 1998 and March 1999. These data are from a larger study investigating the effectiveness of telephone advice provision to non-urgent 999 calls.

Methods-The sample consists of 900 calls triaged as non-urgent using criteria based despatch. Information was gathered on the patient's demographics (gender, age, ethnicity, employment status), relationship to caller, and nature of presenting problem at the time of call.

Results-Of the 900 patients, $43 \%$ (385) were male and $57 \%$ (515) were female. Twenty five per cent of calls were made by the patient; the remainder were third party calls. The most frequent reason for calling the ambulance service was due to fall/collapse $(22 \%)$, abdominal problems $(18 \%)$, head pain $(9 \%)$, and limb problems $(9 \%)$

Conclusions-Priority despatch systems provide opportunities to consider new ways of dealing with potentially non-urgent 999 calls In order to plan alternative responses to these callers, we need to improve understanding of the profile of patients for whom a 999 call is made. This study has contributed to the body of knowledge concerning these "category C" callers and can feed into the local and national programme of developing a range of responses to 999 callers to ensure that patients are responded to appropriately and in a cost effective manner.

Emergency vehicle warning lights; knowledge about the medical green beacon

RUTH STEVENSON, GARY SAYNOR, BRENDAN RYAN Accident and Emergency Department, Wythenshawe Hospital, Southmoor Road, Wythenshawe, Manchester M23 9LT

There is increasing use by doctors of the green light to respond to emergency calls particularly by A\&E staff. The Road Vehicle Lighting Regulations 1989 provides for green beacons by registered doctors but such vehicles are not within the definition of emergency vehicles

There was concern about whether the public could recognise the significance of a green light and would respond appropriately and also whether doctors knew the limitations of emergency driving with a green beacon.

A questionnaire was given to 142 members of the public and 182 medical/paramedical staff to assess their awareness and knowledge about the green beacon that may be used on vehicles driven by medical practitioners.

Fifty eight per cent of male general public drivers only were able to identify a green light and $56 \%$ of female drivers. Fourteen per cent of drivers in the sample failed to identify users of blue lights but identified the green light. In the sample of nurses only $50 \%$ identified correctly green light users while the figure for doctors was only $58 \%$. Thirty seven per cent of the medical group thought that the green beacon driver could exceed the speed limit and $37 \%$ thought drivers could go through red lights. Owners of green lights thought that in $57 \%$ of the sample that the green light allowed them to use excess speed to attend an emergency and in 50\% that they could drive through a red light.

The study has shown the lack of awareness of both the public and the medical profession of the green beacon used by doctors. Also it has highlighted the impression that doctors have that they are able to disregard normal road regulations while driving to an emergency call. Increasing awareness and training is needed to ensure a safe emergency response

\section{Posters: Trauma/Shock}

Acromioclavicular joint sprains: evaluation of the post-injury recovery interval M SHAW, J J MCINERNEY, J DIAS, P A EVANS Department of Accident and Emergency, Leicester Royal Infirmary, Infirmary Close, Leicester LE1 $5 W W$

Introduction - Patients with acromioclavicular joint sprains (ACJ grade 1-2) commonly present to the accident and emergency department. Current practice is to treat such injuries conservatively, with review after a short interval. However, objective data about the expected duration of symptoms after injury are unavailable at present, resulting in patients receiving inaccurate advice. Accordingly, this study was instigated to elucidate the recovery interval expected after an ACJ sprain.

Methods-Patients with possible ACJ injury were assessed in a dedicated shoulder clinic Diagnostic inclusion criteria included: appropriate mechanism of injury, point tenderness 
over the ACJ, absent tenderness around the glenohumeral joint, and normal radiographs. Patients were treated conservatively in a broad arm sling and advice given about analgesia and mobilisation. A validated, structured questionnaire was posted to all patients at an interval after injury of at least nine months. Outcomes assessed by questionnaire were analogue pain scores and scores of daily shoulder function.

Results - 35/47 questionnaires were returned ( $74 \%$ response rate) at a mean interval after injury of 20.1 months (range 10-32 months, SD 6.2 months), with non-responders matching responders for initial assessment and demographic measurements. 14/35 (40\%) patients experienced persistent pain and restricted shoulder function at six months after injury, decreasing to six (17\%) patients at the time of completion of the questionnaire. There was a positive correlation between patients symptomatic at six months and those whose symptoms persist beyond one year $(r=0.6,95 \%$ CI 0.28 to $0.76, \mathrm{p}<0.01)$.

Conclusions - A sizeable proportion of patients with an ACJ sprain may continue to experience adverse symptoms at six months and beyond. Accordingly, clinicians should advise patients of this possibility when reviewed.

Epidemiology and prevention of pedestrian deaths in south east Scotland J P WYATT, A MARTIN, D BEARD, A BUSUTTIL Scottish Trauma Audit Group, Forensic Medicine Unit in the University of Edinburgh and Accident and Emergency Department of the Royal Infirmary of Edinburgh

Aim-To investigate the epidemiology of pedestrian deaths, with a view to prevention. Method-Pedestrian deaths in south east Scotland were prospectively studied over seven years (1992-98) by collaboration between A\&E, Scottish Trauma Audit Group, and the Forensic Medicine Unit. All pedestrians deaths in road traffic collisions were identified using above sources and registrar general records. Circumstances of collisions were obtained from detailed police reports ordered by the procurator fiscal. Prospective clinical data collection and autopsies yielded details of injuries and toxicology. Injury severity scores (ISS) and survival probabilities were calculated for patients reaching hospital using TRISS methodology.

Results-145 pedestrians (79 male) died after collisions with vehicles (including 113 cars): a rate of 2.5 deaths/ 100000 population/year; 76 pedestrians were aged $>60$ years. The following appeared to have "caused" the collisions: pedestrians, 102; drivers, 22; and both, six; (circumstances were unclear in 15 cases). Autopsies were performed on 143 pedestrians (99\%). Toxicology revealed 37 pedestrians had recently consumed alcohol and/or drugs, 26 having blood alcohol levels $>80 \mathrm{mg} / \mathrm{dl}$. Fifty nine pedestrians were found dead or died at scene, three died in transit, 83 survived to hospital. $135(93 \%)$ had ISS >15, with 34 having ISS $=75$. These had 49 unsurvivable injuries involving: 19 thoracic aorta, $13 \mathrm{brain} /$ brainstem, nine upper spinal cord, six heart, and two liver.

Conclusions-Fatal road traffic collisions involving pedestrians are common. Most fatalities involve significant injuries, and many are unsurvivable, reflecting massive forces. There is potential to prevent deaths by improving treatment, but even more by successful injury prevention. Although pedestrians were implicated as causing most collisions, many were elderly and/or under the influence of alcohol/ drugs. Evidence suggests that it is difficult to change behaviour of these groups. Injury prevention measures may be most effectively targeted towards altering drivers' behaviour and towards making motor vehicles more pedestrian friendly in the event of a collision.

\section{Epidemiology of pre-tibial lacerations}

PAUL LEONARD, JOHN O'DONNELL

Accident and Emergency Department, Royal Infirmary of Edinburgh, Lauriston Place, Edinburgh EH3 9YW

Introduction-Pre-tibial lacerations are most commonly seen in the elderly and often require $\mathrm{A} \& \mathrm{E}$ care with prolonged follow up in the community.

Aim - The aim of our study was to examine the causes and mechanism of injury for pre-tibial lacerations presenting to our $\mathrm{A} \& \mathrm{E}$ department in an effort to identify possible preventative measures.

Methods-All patients presenting to the department over a six month period with pre-tibial injuries were included. A brief questionnaire detailing the mechanism of injury was completed by the attending member of medical staff at the time of presentation.

Results - In total 88 patients presented. Most of the injuries $(85 \%)$ occurred in isolation. The majority of the patients were female $(83 \%)$ and elderly $(68 \%$ over the age of 65$)$. Altogether $49 \%$ of patients had sustained their injuries at home or in the garden, $30 \%$ on public transport, in particular while getting on to buses or into taxis, and $7 \%$ occurred at work. The remaining $14 \%$ occurred in a variety of public places.

A total of $45 \%$ of injuries were as the result of a fall or trip, $31 \%$ involved striking the shin against a stationary object, and $15 \%$ occurred when a moving object struck the shin. A large variety of objects were implicated in the injury, in only $20 \%$ of cases the object was a step, in $13 \%$ a seat, and in $9 \%$ the ground.

Discussion-As expected the elderly population are most at risk of pre-tibial injury. The majority of pre-tibial lacerations occur at home and from simple falls. Although a small reduction in injuries may be obtainable by improvements to the steps of public transport it is likely that the best method of injury reduction would be a functional assessment of mobility of elderly patients in their own home.

Hospital response to secondary referrals from a major bomb blast

H J M NICHOLL, B MCNICHOLL

Royal Group of Hospitals, Grosvenor Road, Belfast

Objectives-To describe the acute phase response to secondary transfers from a compound uncompensated major incident (bomb blast) and audit the hospital major incident plan.

Methods-Prospective data collection from patient charts and MTOS data for all secondary transfers to the hospital from the bomb blast.

Result-Twenty one of the 382 victims were received in a five hour period. Six were intubated, three were taken directly to theatre, four to intensive care, and one died after thoracoabdominal surgery in the A\&E department.

Conclusions - The major incident plan should include a section dedicated to secondary transfers. This should improve pre-hospital communication, patient and information flow, trauma team coordination, and back-up services. A relatively small number of high dependency patients in a five hour period required activation of the major incident plan.

Wounding characteristics of ex-military fragmentation grenades used by criminals in Hong Kong

R A COCKS ${ }^{\star}, \mathrm{N}$ Y LAM ${ }^{\star}, \mathrm{L} \mathrm{TAN}^{\star}, \mathrm{R} \mathrm{CHAN}^{\star \star}$, J

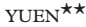

*Accident and Emergency Medicine Academic Unit, Chinese University of Hong Kong and **Hong Kong Police Force

Objective-To investigate the fragment distribution and wounding potential of Chinese PLA type I grenades, and to assess the clinical significance of the findings. There were 50 incidents in 1992 in which criminals used this type of grenade in Hong Kong, and although the territory is now one of the safest major cities in the world, such armaments are known to be available to criminals from the Chinese mainland.

Methods-Two explosions of seized grenades were conducted, the first to assess fragment distribution at 3 and 6 metres and the second to assess fragment distribution and penetration at 2 metres of a $50 \times 35 \times 15 \mathrm{~cm}$ block of $10 \%$ gelatin, a standard ballistic tissue simulant. The block was examined by computed radiography and individual fragments were examined in detail using scanning electron microscopy (SEM).

Results-Few fragments were found to have sufficient energy to cause deep penetrative injury at 3 and 6 metres, and all of those found were over $4 \mathrm{~mm}$ in size. The gelatin block placed at 2 metres was not disrupted by blast but was fissured in the lower ("ground level") part with no loss of shape. Radiographic examination showed that most fragments penetrated at this lower level and revealed a potentially clinically useful "air halo" sign around all fragments of $2 \mathrm{~mm}$ or more in size. SEM demonstrated very sharp fragment edges at all magnifications, with ridges sharper than 1 micron.

Conclusion-This limited but detailed study has demonstrated a radiographic sign of potential importance in assessing patients injured by fragmentation grenades, and gives clues to possible wounding mechanisms. The "micro-sharpness" shown on SEM reveals the potential of the fragment ridges to sever individual tissue fibres and collagen strands.

Heart rate responses to gastrointestinal haemorrhage

D J WHITWELL, M J CLANCY

Accident and Emergency Department, Southampton General Hospital, Tremona Road, Southampton SO16 6SD

Background-Traditional teaching associates an increasing tachycardia with progressive hypovolaemic shock and slowing of the heart rate as a terminal response. Recent work supports such a biphasic pattern in response to atraumatic haemorrhage but with the important difference that the bradycardic response is reversible and not terminal. Such a biphasic response is thought to be caused by increased cardiac vagal afferent $\mathrm{C}$-fibre activity initiating a vasovagal reflex. We were interested in the frequency of this phenomenon, which could be diagnostically confusing when the clinician presumes the bradycardia to be the primary problem rather than a response to haemorrhage. We took gastrointestinal (GI) haemorrhage as an example of atraumatic haemorrhage. We also 
wished to find out if doctors were aware of such a biphasic response to haemorrhage.

Method -All patients entered into the resuscitation room log book of the Bristol Royal Infirmary as having a GI haemorrhage between 1 October 1993 and 30 June 1995 were identified and their notes requested. For each patient their initial heart rate (HR), systolic blood pressure (SBP), and outcome (alive/ dead) at 24 hours were recorded. Statistical comparison of $\mathrm{HR}$ for patients with $\mathrm{SBP}</$ $>100 \mathrm{~mm} \mathrm{Hg}$ was undertaken using Student's $t$ test.

Fifteen junior doctors who could be expected to manage such patients were asked to plot out on graph paper HR and SBP changes with increasing haemorrhage.

Results - Thirty five patients were identified of which the medical records of 20 could be retrieved. One patient was excluded as she was taking a $\beta$ blocker.

There was no statistical difference between the $\mathrm{HR}$ of patients with $\mathrm{SBP}<>>100 \mathrm{~mm} \mathrm{Hg}$. Two patients died within the first 24 hours both with presenting SBP $<100$ and HRs 100 and 68 . Two out of the three patients with $\mathrm{SBP}<100$ and $\mathrm{HR}<70$ survived 24 hours and all three demonstrated an increase in HR and SBP on fluid infusion. One patient (HR 55) was treated with atropine which has been associated with ventricular fibrillation when used in these circumstances.

Twelve of the 15 doctors did not consider slowing of HR to be a response to progressive hypovolaemia and of the three who did, all considered it to be a terminal event.

Conclusion - This study failed to demonstrate the traditionally taught increase in HR associated with decrease in SBP. The absence of tachycardia in hypotensive patients is a real phenomenon. Doctors are unaware that slowing of HR in the presence of hypovolaemic shock occurs and is reversible.

\section{Maxillofacial trauma in North American motor vehicle crashes \\ CHRISTOPHER BROOKES \\ 40 Ravenswood, The Coppice, Bolton BL1 5TL}

In recent years there has been a dramatic decrease in deaths from motor vehicle crashes which reflects improvements in vehicle design and increased public acceptance of safety legislation. These crashes though still account for 40000 deaths annually in America with a resultant economic cost of 150 billion dollars.

In response to this, the National Highway Safety Administration has developed an innovative approach to safety research. This is known as the CIREN project (Crash Injury Research and Engineering Network) and is a collaboration between seven level 1 trauma centres which collect and analyse data relating to every aspect of patients involved in motor vehicle crashes. The injuries received are then correlated to the deformation of the vehicles involved after their examination by expert vehicle examiners.

I studied 20 patients who presented to the University of Michigan with facial trauma as part of their catalogue of injuries, between 1996 and 1998. The most common sources of facial injury in these patients were the steering wheel and the vehicle "A" pillar.

In airbag deployed collisions, no patient, whether restrained or not, suffered an injury from the steering wheel. Injuries from this structure were principally to belted occupants, in crashes which resulted in intrusion of the steering column.
By contrast, where an airbag deployed, the A pillar was most often the injury source (five patients in total). A detailed analysis of these patients, including the principal direction of forces involved in the collision is presented.

Their facial injuries were accurately classified and a comparison between these and the general injury severity score was made. Generally, the facial injuries were much less severe in relation to the other injuries sustained, but two of these five patient received serious globe injuries. An explanation for these additional injuries is presented and the particular risks encountered by unrestrained occupants of small stature when an airbag deploys are highlighted.

Finally, recommendations are made regarding the necessity for vehicle manufacturers to consider further modification to the A pillar structure as this remains a significant source of facial trauma even when there is airbag deployment.

Neuroradiological and neuropsychological correlates of mild traumatic brain injury

D L MASON, D W YATES, E BERRY, D HUGHES, J THORNE

Department of Emergency Medicine, Hope Hospital, Stott Lane, Salford M6 8HD

Mild traumatic brain injury (MTBI) accounts for between $60 \%$ and $80 \%$ of admissions fo head trauma. Approximately $20 \%$ of patients with MTBI develop deleterious secondary morbidity but evidence for the aetiology of these post-concussional sequelae remains meagre.

For this ongoing study, 50 patients meeting the MTBI criteria underwent neuropsychological and neurological examination within 72 hours of trauma and again three months after injury. A neuroradiological examination consisting of sagittal volume MPRAGE, axia T2 gradient echo, and axial FLAIR magnetic resonance sequences was additionally conducted within 72 hours of trauma. Forty per cent of patients demonstrated non-specific MR abnormalities, which may be consisten with small non-haemorrhagic contusions. These patients underwent further neuroradiological evaluation three months after injury.

Patients' performance on an exhaustive neuropsychological test battery was compared with normative data. Significant impairment were found on tests of memory, attention, and executive function within 72 hours of injury. In addition, patients with abnormal MR scan demonstrated significantly poorer performance on measures of attention and executive function compared to those with initially normal MR scans. This significantly impaired performance was found to be resolved at three month follow up.

Patients who, at 72 hours after injury, scored below normal limits on tests of attention, were found to be lower in mood and reported increased somatic awareness at three months after injury. Time off work six month after injury was significantly higher in those patients who showed memory impairments at 72 hours. Preliminary results suggest that patients with specific impairments on attentional tests are more likely to show abnormalities on MRI and increased emotional distress. This raises the possibility that attentional difficulties and later increased somatic symptoms may be attributable to diffuse axonal shearing.
Incidence and clinical course of whiplash associated disorder in children

RUSSELL BOYD, RAVI MASSEY, LORCAN DUANE, DAVID YATES

Department of Emergency Medicine, Hope Hospital, Salford M6 $8 H D$

Background-Acute neck sprains after road traffic accidents, now termed whiplash associated disorders (WADs), have been described as a "modern epidemic". Much research has been written on this topic in recent years. This literature has almost exclusively pertained to adults. Only one study has involved itself with children, quoting an incidence rate of $29 \%$ in children. This one year project has been designed to exclusively look at the problem of WAD in children.

Objective - To determine the incidence, severity, and course of WAD in children aged 4-16 after involvement in road traffic accidents as passengers.

Methods - Prospective surveillance of all paediatric attendances to three urban $\mathrm{A} \& \mathrm{E}$ departments after road traffic accidents for an initial three month period. Follow up was performed using an initial telephone interview followed by clinical review using the Quebec Task Force criteria for WAD assessment.

Results-Thirty five children were identified as having been involved in a road traffic accident as passengers. Twelve experienced a WAD after the accident. Ten experienced a WAD grade I and two a WAD grade II event. Nine of the grade I WAD children recovered inside seven days with the remaining one child recovering inside 14 days. All the WAD grade II children recovered inside 14 days. Seven of the children with WAD developed symptoms inside 24 hours with five children developing symptoms at $24-48$ hours.

Conclusion-WAD in children has a lower incidence than that previously suggested in earlier studies. The incidence of WAD in children is less than that often quoted in adult passengers. The clinical course of WAD is more favourable than in adults. Further work is required to elucidate the reasons for these findings.

Does cause of injury predict the subsequent development of psychological disorder following accidental injury?

$S$ M MASON, J WARDROPE, G TURPIN

Accident and Emergency Department, Northern General Hospital, Herries Road, Sheffield S5 $7 A U$

This study aimed to evaluate the effect of actual and perceived cause of injury on psychological outcome.

Male A\&E attenders who were admitted to hospital after accidental injury were recruited and prospectively followed up at six weeks, six months, and 18 months $(n=210)$. The cause of injury was documented at initial interview according to the Major Trauma Outcome Study criteria. In addition details about the cause of the accident were recorded such as blame for the accident, involvement of alcohol in the accident, others being injured at the time of the accident, and ability of patients to predict the accident. At follow up patients completed a semistructured interview and standardised questionnaires documenting psychological symptoms such as anxiety, depression post-traumatic stress disorder symptoms, and psychiatric caseness

A relationship between psychological outcome, cause, and perceptions of the accident were investigated using two tailed Pearson correlation. Variables relating to cause of 
injury were also subjected to linear regression analysis to evaluate their ability to predict psychological outcome. A relationship was found between the development of more severe psychological symptoms and those patients who had suffered road traffic accidents, assaults, or work related injury. In addition, those patients who believed their accident was not predictable, where others were injured, where alcohol was involved, and where patients believed they could have prevented the accident were predicted to have a worse psychological outcome.

These results suggest a relationship exists between actual cause of injury, individual interpretations of accidents, and psychological morbidity. The findings confirm the important role that guilt and blame have in the development of a range of psychological disorders after accidental injury.

Relationship of injury severity to psychological outcome among accidentally injured males

S M MASON, J WARDROPE, G TURPIN

Accident and Emergency Department, Northern General Hospital, Herries Road, Sheffield S5 $7 A U$

A small number of studies have tried to identify the relationship between severity of injury and the subsequent development of psychological distress as a result of injury. The results have yielded conflicting findings.

This study prospectively followed up consecutive male $A \& E$ attenders $(n=210)$ who were admitted to hospital after accidental injury. Details of the injures received were recorded at the time of admission and an injury severity score (ISS) calculated. Patients were followed up at six weeks, six months, and 18 months after injury and completed a semistructured interview and standardised questionnaires. The follow up assessed patients for psychological symptoms such as anxiety, depression, post-traumatic stress disorder symptoms, and psychiatric caseness. A relationship between ISS and psychological outcome after injury was investigated using two tailed Pearson correlation. The ISS was entered into linear regression equations to evaluate its ability to predict psychological outcome.

Pearson correlation coefficients varied between -0.17 and 0.13 and were not significant at the $p=0.05$ level. From the regression equations $\beta$ values were not found to significantly contribute to the variance in psychological outcome among responders at each follow up time point.

This study has shown that injury severity has a non-significant relationship with psychological outcome, and is not a factor in predicting psychological disorder after accidental injury.

\section{Posters: Diagnostic Testing}

Is a chest pain observation unit likely to be cost saving in a typical UK hospital?

$S$ W GOODACRE, F P MORRIS, J A ARNOLD, $\mathrm{K}$ ANGELINI

Accident and Emergency Department, Northern General Hospital, Herries Road, Sheffield S5 $7 A U$

Background-Data from the United States (US) suggest that using a chest pain observation unit (CPOU) for low risk patients saves between $\$ 567$ and $\$ 2030$ per case compared with hospital admission. However, the cost of routine hospital admission for such patients in the US varies from $\$ 2089$ to $\$ 3961$ and often includes interventional cardiology costs. CPOU care in the United Kingdom (UK) will only produce similar savings if the cost of routine hospital admission is comparable. We aimed to review our current practice to determine the proportion of patients suitable for CPOU evaluation, the cost per case of those admitted and to compare this with control groups in American studies.

Method - 250 patients were randomly selected from those admitted with chest pain after A\&E attendance between January and June 1998. Two independent observers reviewed the case notes to determine who would have been suitable for CPOU management. Resource use of those selected was then deter mined.

Results-97 (39\%) patients were suitable for CPOU care (mean age 56 years, $56 \%$ male) Mean length of stay was 51 hours (median 24). Inpatient investigations were limited to $x$ rays, ECGs, and blood tests in all but three patients; 30 underwent outpatient exercise testing. Only two patients had angiography, one had PTCA and one CABG. Mean cost per patient was estimated at $£ 470$ with cardiac catheterisation and surgery included, $£ 360$ without.

Conclusion-The Ccost savings from CPOU care demonstrated in US studies wer achieved by comparison with relatively high inpatient costs and should not be extrapolated to the UK. Economic evaluation of the CPOU should be repeated in the UK. The inclusion of cardiac catheterisation and surgery costs is controversial but an important determinant of cost effectiveness.

Increasing the detection of alcohol misuse using the Paddington alcohol tes (PAT)

J S HUNTLEY, C BLAIN, S HOOD, R TOUQUET

Department of Accident and Emergency Medicine, St Mary's Hospital, Praed Street, London W2 $1 N Y$

Introduction-Despite establishing the PAT fo alcohol misuse with an encouraging success rate for subsequent counselling, both detection and referral rates have remained lowe than expected. This is in the face of positive attitudes of accident and emergency staff towards improving the response to alcohol related attendances.

Objective - To audit and increase PAT uptake, and to assess SHO attitudes to the PAT and audit.

Methods-Audit of SHO notes over a fou month period, during which the incumben team was unchanged, with feedback and awareness of ongoing audit in the middle two months only; every fourth day was audited (seven days a month).

Results-The notes of 1737 (98.6\% of those fulfilling inclusion criteria) were analysed, $61.1 \%$ (1062) had one (or more) condition defining them as PAT-positive. Initially, PAT uptake was poor $(61.5 \%$ of PAT-positive patients having no documentation of alcoho history). Uptake of the PAT (both positive and negative) was significantly increased ( $\chi^{2}$ test: $\mathrm{p}<0.0001$ ) in each of months 2 and 3 , with the percentage missed (PAT not done) being $39.6 \%$ and $21.7 \%$ respectively. In month 4 there was a significant $\left(\chi^{2}\right.$ test: $\left.p=0.003\right)$ reversal in this measure $(32.6 \%)$. The proportion of patients identified as PAT-positive was $3.4 \%(1), 9.6 \%(2), 14.3 \%$ (3), and $8.2 \%$ (4) (\%PAT-positive, with month in parenthe- ses). The response to audit/feedback showed marked variation between SHOs. Questionnaire analysis showed SHOs to be committed to the principles underlying the PAT and the importance of early detection of alcohol misuse.

Conclusions-Audit significantly improved SHO performance. More patients were subsequently identified as PAT-positive, and referred to the alcohol health worker. Because SHO performance declined with withdrawal of feedback the case is made for ongoing audi in order to increase the detection of alcohol misuse.

Awareness and use of clinical decision rules: an international study

I D GRAHAM, I G STIELL, A LAUPACIS, L MCAULEY, $M$ A HOWELL, M CLANCY, ET AL

Accident and Emergency Department, Queen Alexandra Hospital, Portsmouth PO6 3LY

Objectives-To determine emergency physicians' awareness and use of the Ottawa ankle and knee rules and their attitudes towards clinical decision rules in general.

Design - Cross sectional self administered mail survey.

Setting - USA, Canada, UK, France, Spain.

Participants-Random samples of $500 \mathrm{mem}$ bers of each of the national associations for emergency medicine in USA, Canada, UK, and Spain, and all members of the French national association.

Outcome measures-Awareness of the Ottawa ankle and knee rules, reported use of these rules, attitudes towards clinical decision rules. Results-A total of 1769 physicians responded. $70 \%$ of emergency doctors were aware of the ankle rules in all countries except Spain. Approximately $90 \%$ of those who were aware of the rules used them frequently. Only $29 \%$ of UK emergency physicians were aware of the knee rule and fewer than half of these reported using it frequently. Most respondents felt that clinical decision rules are good educational tools, are intended to improve quality of care, and a convenient source of advice. Some felt that they protect against complaints and legal claims. Few felt that they were too difficult or time consuming to use. Conclusions-This is the largest international survey of clinical decision rule use by emergency physicians. There are large differences between nations in knowledge of, and use of, the rules. Further work will look to increase dissemination and implementation of such rules in emergency departments.

Is computerised radiology the way forward?

VICTORIA GOODWIN, MARY HIGGINS, SARAH SHEWRING, PETER RICHMOND

Emergency Unit, Heath Park, University Hospital of Wales, Cardiff CF14 4XW

Introduction-The advent of computerised radiography (CR) and digital technology may make the traditional plain radiograph a relic of the past. The A\&E department at Cardiff Royal Infirmary relocated to the University Hospital of Wales on 22 March 1999. A computerised digital radiographic system was installed in the new department. The aim of our study was to examine the impact of the introduction of CR to the $\mathrm{A} \& \mathrm{E}$ department of our hospital. Our hypothesis was that viewing times with CR compared with plain radiographs would be prolonged.

Materials and methods-Recordings were made of the time spent by A\&E clinicians 


\begin{tabular}{llllllllll}
\hline & SXR & Facial & C spine & CXR & $\begin{array}{l}\text { Pelvis/ } \\
\text { hips }\end{array}$ & $\begin{array}{l}\text { Rest of } \\
\text { spine }\end{array}$ & AXR & $\begin{array}{l}\text { Upper } \\
\text { limb }\end{array}$ & $\begin{array}{l}\text { Lower } \\
\text { limb }\end{array}$ \\
\hline Plain radiograph $(\mathrm{n}=316)$ & 40 & 48 & 116 & 80 & 116 & 28 & 8 & 40 & 54 \\
CR (n=282) & 76 & 92 & 157 & 85 & 157 & 88 & 90 & 81 & 93 \\
\hline
\end{tabular}

viewing plain radiographs over a three week period before relocation. The exercise was then repeated with CR in the new unit. All clinicians received a training session regarding CR operation.

Results - The $x$ rays were grouped as above (table 5). The mean time to view each group in seconds was documented.

The results show that all viewing times using CR were longer than plain radiographs.

When "retrieval time" (that is time taken for computer to find a particular image) was taken into account, the actual viewing time of images using CR was similar to plain radiographs. This would suggest that any increase in viewing times is related to computer process.

Discussion -Delays were encountered with CR which need to be taken into account when implementing such a system in an $A \& E$ department. There is a potential "knock-on" effect for patient process. Potential problems during retrieval were: (1) $x$ rays not archived in the $x$ ray department, (2) $x$ rays sent to wrong triage area, (3) patient movement within the department, (4) incorrect form filling, (5) computer malfunction.

Conclusion-Viewing times are prolonged using CR due to a mixture of human error and computer process.

Does ultrasound have a role in the clinical diagnosis and management of fractured ribs?

T H RAINER, K L LAW, J F GRIFFITH, C METREWELI, $\mathrm{R}$ A COCKS

Accident and Emergency Medicine Academic Unit, Chinese University of Hong Kong and Prince of Wales Hospital, Hong Kong

Background and objective-The diagnosis of rib fractures after isolated moderate chest injury is potentially inaccurate. It is usually made on clinical grounds without objective confirmation as radiographs are thought to be insensitive and rarely influence management. Ultrasound is a non-invasive procedure, which may improve the accuracy of diagnosis when compared with clinical and/or radiographic assessment. This study compared ultrasound and plain radiography in the detection of rib fractures, and sought to determine whether chest pain, work absence, and respiratory infections are related to rib fractures.

Methods-In a prospective, observational study of patients with blunt chest trauma attending a university hospital emergency department, initial plain radiography and early ultrasonography (US-1) were compared with a second ultrasound examination performed three weeks later (US-2). Clinical aspects were recorded at US-1, US-2, and at telephone follow up. The gold standard for detecting rib fractures was US-2.

Results - Of 86 adults (median age 48 years; range 24-89) with chest injury, 50 (58\%) returned for US-1 and $38(44 \%)$ for US-2. Eight rib fractures were detected in 6/50 (12\%) patients by radiography and 83 fractures in $39 / 50(78 \%)$ patients at US-1. At US-2, 4/38 (11\%) patients had fractures not detected at US-1. The sensitivity of radiography was $21 \%$ (95\% confidence interval (CI) $8 \%$ to $33 \%$ ) and that of the US-1 was $88 \%$ (95\% CI $70 \%$ to
$90 \%)$. There was no difference in total sick leave, initial or later pain scores between those with or without fractures. At telephone follow up, respiratory infections were reported by $6 / 13$ $(46 \%)$ patients with rib fractures and $0 / 5$ of those without rib fracture (Fisher's exact test, $\mathrm{p}$ $=0.06$ ). Number of rib fractures correlated positively with the development of respiratory infection (Mann-Whitney U test, $\mathrm{p}=0.03$ ). Conclusion-Ultrasound is highly sensitive in detecting rib fractures. Patients with rib fractures were more likely to develop chest infections.

Infrared tympanic thermometry in lowered deep body temperature

N S S MASKERY, C J CAHILL

Accident and Emergency Department, Queen Alexandra Hospital, Cosham, Portsmouth, Hant PO6 $3 L Y$

Aim-To investigate the accuracy of infrared tympanic membrane thermometry in the measurement of subnormal temperature.

Method-Six healthy undergraduate students had their deep body temperature lowered under laboratory conditions by total immersion in cold water. Their deep body temperatures were monitored using an aural thermistor placed adjacent to the tympanic membrane and/or by a rectal thermistor (reference temperature). Their temperature was lowered either until the core temperature had reached $35^{\circ} \mathrm{C}$ or they found the conditions unbearable. For each tenth of a ${ }^{\circ} \mathrm{C}$ drop in deep body temperature measured by reference temperature, a tympanic temperature measurement was taken from the available ear using a standard IVAC "Core-Check" infrared tympanic thermometer.

Results-In the eight cold water immersions the core temperature was lowered by a mean of $1.52^{\circ} \mathrm{C}$ from a mean aural temperature (Tau) of $36.98^{\circ} \mathrm{C}$ to $35.65^{\circ} \mathrm{C}$ and by $1.97^{\circ} \mathrm{C}$ from a mean rectal temperature (Tre) of $37.33^{\circ} \mathrm{C}$ to $35.36^{\circ} \mathrm{C}$. The tympanic infrared temperature (Tir) dropped by a mean of $1.69^{\circ} \mathrm{C}$ from a mean of $36.44^{\circ} \mathrm{C}$ to $34.75^{\circ} \mathrm{C}$. In these experiments the tympanic thermometer always under-read, by a mean of $0.71^{\circ} \mathrm{C}$ between Tau and Tir, and by $1.08^{\circ} \mathrm{C}$ between Tre and Tir.

Conclusion-The tympanic thermometer has been shown to be inaccurate in measurement of actual deep body temperature over a range of temperatures when compared to "gold standard" methods of temperature measurement, although incremental temperature change can be shown graphically to paralle that of the reference temperatures. We conclude that its use for the measurement of body temperature in the hospital setting, especially in the hypothermic patient, can be misleading and potentially dangerous.

Decision making at the "front door"-a management plan for suspected and confirmed deep vein thrombosis

K HENDERSON

Accident and Emergency Department, Homerton Hospital, Homerton Row E9 6SR

Venous thromboembolism is common. Only about $25 \%$ of patients investigated for deep vein thrombosis (DVT) on clinical suspicion are shown to have thrombus on objective testing. Undiagnosed DVT may be fatal but the treatment is effective, although potentially dangerous. As most patients do not have the target diagnosis but need investigation on suspicion, bringing diagnostic services as near as possible to the "front door" allows efficient management of these patients. Excluding the diagnosis in the $A \& E$ department frees up resources for other patients.

We looked at our practice at the Homerton Hospital and identified four major process problems and two major clinical problems in the management of these patients.

Process problems - (1) Delays in making a definitive diagnosis; (2) unnecessary admissions to hospital; (3) unplanned requests to the radiology department for Doppler tests; (4) nursing and medical time and resources being used to administer intravenous drugs.

Clinical problems - (1) Patients receiving drug treatments for a condition they did not have; (2) inadequate treatment with standard heparin.

We developed a diagnostic care pathway incorporating new arrangements with radiology and new technologies: D-dimer testing, a strain gauge plethysmograph (AMT Venometer), and low molecular weight heparin. Results-Interim analysis at four months:

- 169 patients have been managed by the pathway (111 A\&E or outpatients, 58 inpatients)

- $33(20 \%)$ were shown to have a DVT

- 78 admissions have been avoided

- 58 patients have had the diagnosis excluded on the day of presentation

- Request for Doppler ultrasound have been reduced by $40 \%$

- Low molecular weight heparin has been adopted as standard for treating DVT

- Patients with confirmed DVT are now being successfully managed as outpatients as a result of the success of the pathway for suspected DVT

This paper will show the pathway and some analysis of particular patient groups (pregnancy).

Ottawa knee rule in Birmingham: part one of a prospective validation study K LENDRUM, S PAPPASAVVAS, I K DUKES Accident and Emergency Department, Russells Hall Hospital, Dudley, West Midlands DY1 $2 \mathrm{HQ}$

Objectives-To determine prospectively the number of acute knee injuries, $x$ rays requested and fractures detected, as a pilot study of a validation of the Ottawa knee rule. Patients-All adults presenting to a district general hospital A\&E department over six months within seven days of acute knee injury. Exclusion criteria were: age under 18 years, pregnancy, return for reassessment, referral with pre-existing $x$ rays, penetrating or isolated skin injury, multiple injuries, altered level of consciousness, or restricted communication with the patient.

Methods-Emergency nurse practitioners and medical staff assessed patients and requested $x$ rays of the knee according to normal practice; $x$ rays were reported by a radiologist blinded to clinical data. Data were collected prospectively and analysed on a computer spreadsheet. Outcome measures included number of knee injuries, $x$ rays, and fractures and the Ottawa rule criteria. The sensitivity and specificity of the Ottawa knee rule were determined retrospectively. 


\begin{tabular}{llll}
\hline Chemokine tested & $\begin{array}{l}\text { Median IL-8 } \\
\text { concentration }(\mu \mathrm{g} / \mathrm{ml})\end{array}$ & $\begin{array}{l}\text { Median GRO } \\
\text { concentration }(\mu \mathrm{g} / \mathrm{ml})\end{array}$ & $\begin{array}{l}\text { Median ENA } 78 \\
\text { concentration }(\mu \mathrm{g} / \mathrm{ml})\end{array}$ \\
\hline Patients $(\mathrm{n}=35)$ & 0.086 & 0.322 & 3.56 \\
Controls $(\mathrm{n}=8)$ & 0 & 0 & 1.906 \\
Wilcoxon test (p value) & 0.043 & 0.012 & 0.025 \\
\hline
\end{tabular}

Results - Of 361 patients, 218 (60\%) were eligible for the study; 119 (55\%) had an $x$ ray and 14 fractures (6\%) were identified. Retrospective application of the knee rules identified 32 additional patients who needed an $x$ ray and 32 patients who had unnecessary $x$ rays. Eighty seven patients who had $x$ rays and 66 without were correctly identified by the rule; one patient was wheelchair bound and therefore the rule was felt to be nonapplicable. The Ottawa rule had sensitivity and specificity of $86 \%$ and $47 \%$ respectively. The rule missed one avulsion fracture (lateral ligament) and an old fracture.

Conclusion-The knee rule is less sensitive than in Ottawa and may not reduce $x$ ray rate. Further prospective study will validate the rule in more detail.

\section{Posters: Therapeutics/Toxicology}

Partial rotator cuff tears of the shoulder: a randomised controlled trial of subacromial injection of methylprednisolone

J J MCINERNEY, J DIAS, S DURHAM, P A EVANS

Department of Accident and Emergency, Leicester Royal Infirmary, Infirmary Close, Leicester LE1 $5 W W$

Introduction - The optimal management of partial rotator cuff injuries of the shoulder remains controversial. Patients are managed with steroid injections, and/or analgesia plus physiotherapy. Currently, no study has successfully validated such use of steroids. Accordingly, a powered, randomised control trial was instigated to evaluate the advantages of subacromial injection of methylprednisolone over conservative treatment.

Method-Consecutive patients with possible partial rotator cuff tears were reviewed at one week. Inclusion criteria for a diagnosis of partial rotator cuff tear included: traumatic mechanism, greater tuberosity tenderness, painful arc, and complete resolution of disability after bupivicaine block. Exclusion criteria included: age $<16$ years, chronic shoulder disease, acromioclavicular tenderness, and abnormal shoulder radiograph. Patients were randomly allocated to receive either one immediate subacromial injection of $40 \mathrm{mg}$ methylprednisolone (group S) or no injection (group $\mathrm{N}$ ). Initial outcomes measured were: analogue pain score (0-10) and active abduction (nearest $5^{\circ}$ ), repeated at three, six, and 12 weeks. All patients were instructed in analgesia usage and given identical shoulder exercises.

Results-Of 279 patients reviewed over three years, 90 met the inclusion criteria (6/90 patients were lost to follow up). 50 patients were randomised to group S, 40 to group N. Mean pain score improvement at 12 weeks was comparable $(\mathrm{S}=4.95, \mathrm{~N}=4.44)(\mathrm{p}>0.1$, $95 \%$ CI 0.16 to 0.86 ). In patients aged $>40$ years group $S$ had significantly higher mean improvement in abduction at completion $\left(64.28^{\circ}\right)$ than group $\mathrm{N}\left(34.63^{\circ}\right)(\mathrm{p}<0.02,95 \%$ CI 1.29 to 58.01). Conversely, in patients aged $<40$ group $S$ had lower mean improvements in abduction $\left(40.55^{\circ}\right)$ than group $\mathrm{N}$ $\left(77.73^{\circ}\right)$, though this was not significant $(\mathrm{p}=0.1,95 \%$ CI 2.06 to 72.29$)$
Conclusions-Methylprednisolone injection is more efficacious than conservative treatment alone in some patients. This benefit appears age dependent and, consequently, such treatment should be reserved for patients aged $>40$ years.

Hormonal emergency contraception: is it an accident or an emergency? The patients' perspective

SARAH WOOLLEY

Accident and Emergency Department, Russells Hall Hospital, Dudley

Objectives-A doctor administered questionnaire was conducted to determine patients preferred options for obtaining hormonal emergency contraception (EC). Emphasis was placed on provision by $\mathrm{A} \& \mathrm{E}$ departments and pharmacists.

Setting-An A\&E department and four family planning clinics, West Midlands.

Subjects - 854 women, aged between 13 and 50.

Methods-854 women were interviewed using a questionnaire about EC. Interviewees were anonymous.

Results - $60 \%$ of pregnancies were unplanned, of these $29 \%$ were terminated. $59 \%$ of women had taken $\mathrm{EC}$, with $68 \%$ of women requiring EC because of a failure of regular contraception. Only $12 \%$ had obtained EC from A\&E $82 \%$ of the women interviewed would prefer to obtain EC from family planning clinics but $75 \%$ of the women sampled believe that accident and emergency departments should provide EC (mainly because of 24 hour access) and $59 \%$ believe that it should be available in pharmacies.

Conclusion-A large number of pregnancies are unplanned and of these $29 \%$ are terminated, with psychological and financial consequences. Hormonal EC is safe and effective and is often required because regular contraception has failed. Several studies have highlighted the importance of timing in taking EC and, as there is overwhelming support in this study for the provision of EC by $A \& E$ departments, perhaps those not providing EC should reconsider.

Effects of pre-hospital nalbuphine on emergency room analgesia

A P VOLANS

Accident and Emergency Department, Scarbor ough Hospital, Woodlands Drive, Scarborough, North Yorkshire YO12 6QL

Nalbuphine is a partial agonist opioid analgesic that has a licence for use by trained paramedic staff in the UK. There is a perception that nalbuphine can cause problems with opiate analgesia.

A prospective study was carried out of 48 consecutive cases treated with nalbuphine in the field by paramedics working to protocol Of 48 patients, 43 patients received $10 \mathrm{mg}$ or more of nalbuphine and 38 requested further analgesia once delivered to the department.

Remembered preinjection pain score $(0-5)$ and current pain score were recorded.

Of 33 patients with a remembered pain score of 5,18 had a reported score on arrival of 5. These all attended between 30 and 90 minutes after injection; $16 / 18$ patients had had a dose of over $15 \mathrm{mg}$ of nalbuphine.

Of eight patients with a remembered pain score of 4 , six had no relief or an increase in pain by their attendance to the department. Overall $24 / 41(58 \%)$ had no improvement in their pain symptoms.

Thirty one patients required morphine analgesia given by titrated intravenous injection. Fifteen $(48 \%)$ required over $10 \mathrm{mg}$ of morphine compared with a 10/131 (8\%) requirement for more than $10 \mathrm{mg}$ morphine during the same period for patients not given nalbuphine.

Supplementary techniques were used to achieve pain relief in 20 patients including diclofenac injection, nerve block, haematoma block, and nitrous oxide and manipulation of dislocations under midazolam.

A significant problem in achieving adequate pain control was reported in $18 / 48$ patients.

It is suggested from observation of the time course and pain reporting that after 30 minutes, 25 of 48 patients were in severe pain and that this pain was made more difficult to treat by the presence of nalbuphine in the system.

Proinflammatory chemokine concentrations are raised in plasma of patients with late paracetamol poisoning

A L JONES, K J SIMPSON

National Poisons Information Service (London), Guys and St Thomas' NHS Trust, London SE14 $5 E R$

Background - The appearance of specific types of leucocytes in inflammatory infiltrates are governed by cell specific chemoattractants called chemokines. If chemokines are involved in paracetamol induced injury, then design of inhibitors will become an important therapeutic goal. The aim of our study was to evaluate if cellular chemokines were present in patients poisoned by paracetamol.

Methods - 23 patients (9M:14F; mean age 37.6 years) presenting late (19.2 hours; range 5-50) with paracetamol poisoning (mean $22 \mathrm{~g}$ \pm 13.1 ) were studied. In 10 patients samples were taken before and after $N$-acetylcysteine; three samples were taken from one patient. Samples were also taken from controls of similar age, not exposed to paracetamol. Assays for various chemokines were carried out by ELISA.

Results-The results are shown in table 6 .

Conclusions - The chemokine concentrations were significantly raised in patients presenting late with paracetamol poisoning compared with controls. IL-8, GRO, and ENA 78 attract neutrophils but not monocytes and a pathogenic role in the development of injury due to paracetamol can now be hypothesised.

A comparative study of analytical methods for assay of plasma paracetamol concentration in patients presenting late with paracetamol poisoning

A L JONES, D JARVIE, L F PRESCOTT

National Poisons Information Service (London), Guys and St Thomas'NHS Trust, London SE14 $5 E R$

Background - Newer bench top assay methods have been developed for assay of plasma paracetamol in the emergency department. The aim of this study was to compare the AcetaSite (colorimetric test card) and Cambridge Life Sciences Cobas (electrochemical) analytical 
methods with the gold standard HPLC method for measuring paracetamol.

Methods-23 patients (9M:14F; mean age 37.6 years) presenting late (19.2 hours; range 5-50) with paracetamol poisoning (mean $22 \mathrm{~g}$ \pm 13.1 ) were studied. In 10 patients samples were taken before and after $\mathrm{N}$-acetylcysteine; three samples were taken from one patient. Venous blood was taken centrifuged immediately at $3000 \mathrm{rpm}$ and stored at $-40^{\circ} \mathrm{C}$. Results-Results are shown in table 7.

Table 7

\begin{tabular}{lll}
\hline Comparison & $\begin{array}{l}\text { Paired } t \text { test }(p \\
\text { value) }\end{array}$ & $\begin{array}{l}\text { Pearson } \\
\text { correlation } \\
\text { test }(r)\end{array}$ \\
\hline HPLC $v$ Cobas & 0.8 & 0.986 \\
HPLC $v$ AcetaSite & 0.002 & 0.970 \\
\hline
\end{tabular}

Conclusions-The AcetaSite method showed greater variation from the standard HPLC method than the Cobas method. The most likely source of the difference was a calibration error within the AcetaSite method. There was no evidence for interference by $\mathrm{N}$-acetylcysteine in either the Cobas or AcetaSite methods of assay.

Pre-hospital nalbuphine administration and subsequent analgesia requirements in accident and emergency

K P G HOULIHAN, I LAING, P A LEONARD

Accident and Emergency Department, Royal Infirmary of Edinburgh, Lauriston Place, Edinburgh EH3 9YW

Introduction - Nalbuphine hydrochloride is an agonist-antagonist opioid and could alter requirements for subsequent opiate administration.

Objective-To analyse the pattern of prehospital nalbuphine administration and to determine the opiate requirements of these patients while in the A\&E department.

Methods - A retrospective analysis was performed on 100 consecutive patients who received pre-hospital nalbuphine. Patients were identified from the ambulance service database and additional information was retrieved from A\&E notes. Age, sex, time, and mechanism of injury or illness of all patients were recorded. The timing and dose of nalbuphine were obtained. Patients who required additional analgesia were identified. The nature, timing, and dose of this analgesia were noted. The use of an opioid antagonist was recorded. The disposal of all patients was obtained.

Results-Sixty two patients were male and 38 were female with an age range of 13-99 years $($ median $=59.5)$. Forty patients sustained fractures, 10 had joint dislocations, 12 had soft tissue injuries, and two had cutaneous burns. Thirty four individuals presented with chest pain and two with abdominal pain. Nalbuphine dosage ranged from $0.5-20 \mathrm{mg}$ $($ median $=10)$. Time from the onset of pain to nalbuphine administration varied from 7-120 minutes (median $=22.5)$. Fifty seven patients required additional opiates while in the $\mathrm{A} \& \mathrm{E}$ department. Dosage of intravenous morphine ranged from $4-45 \mathrm{mg}$ (median $=10)$ and this was administered 10-210 minutes (median = 45) after nalbuphine delivery. Two patients required reversal of respiratory depression secondary to morphine administration. Eighty two patients were admitted, one died, and the remaining 17 were discharged.

Conclusions-Almost half of patients who received pre-hospital nalbuphine did not require additional opioid analgesia while in A\&E. There were no significant complication from nalbuphine administration. Within the group of patients who required additional opioid analgesia the amount needed varied considerably. There is no clear evidence of excessive opiate requirement after nalbuphine administration.

Antidote availability in accident and emergency departments

MARY HIGGINS, RUPERT EVANS

Emergency Unit, University Hospital of Wales, Heath Park, Cardiff CF14 4XW

Introduction - "With some sweet oblivious antidote cleanse the stuff'd bosom of that perilous stuff which weighs upon the heart?" (Macbeth, William Shakespeare).

While Macbeth's "sweet oblivious antidote" may sound attractive, the current definition of an antidote as a "therapeutic substance administered to counteract the adverse effect of a specific xenobiotic" encompasses a wide variety of antidotes of variable efficacy.

The aims of our study were: (1) to determine antidote availability to A\&E departments in a UK setting; (2) to establish awareness of existing UK guidelines.

Materials and methods-The BAEM 1998/99 directory was used to identify major units in Wales and the south west of England. Chief pharmacists were requested to provide stocklist of antidotes and to complete a questionnaire regarding awareness of existing 1986 guidelines. International Programme on Chemical Safety (IPCS) 1997 recommendations were used as the gold standard.

Results-Thirty four of 43 departments responded $(77 \%)$. More than half of pharma cists surveyed $(n=20)$ were unfamiliar with existing guidelines. Few used these in practice $(n=7)$ or felt they were useful $(n=4)$. The majority $(n=29)$ felt that up-to-date recommendations would be relevant.

No department held all 34 antidotes (range 7-33, mean 13). $\mathrm{N}$-acetylcysteine, atropine, and naloxone were available in all. Three departments $(9 \%)$ had no cyanide antidote while four $(12 \%)$ did not stock any heavy metal chelator. Calcium gluconate and methylene blue were held by $41 \%$ and $32 \%$. Newe antidotes including hydroxycobalamin were held by two departments (6\%) while 4-methylpyrazole and the chelating agents DMSA and DMPS were not available in any.

A trend exists whereby larger departments tend to stock more antidotes.

Conclusion-Great variability exists regarding antidote availability to A\&E departments. Agents that are important in the managemen of life threatening poisoning may not be available in a timely fashion.

Review of the evidence base regarding antidote use is necessary to establish up-to-date recommendations relevant to $\mathrm{A} \& \mathrm{E}$ practice.

Use of anti-D immunoglobulin in the management of threatened miscarriage in the accident and emergency department

L WEINBERG

Accident and Emergency Department, Royal Cornwall Hospital, Truro, Cornwall TR1 3LF

In March 1999, the guidelines for the use of anti-D immunoglobulin for rhesus prophylaxis were revised. Anti-D immunoglobulin is no longer recommended for rhesus negative women after a threatened miscarriage less than 12 weeks' gestation. If bleeding is heavy, repeated or if there is associated abdominal pain, the guidelines still recommend its use.

A retrospective study over a 17 month period was conducted looking at women less than 12 weeks' gestation who presented with a threatened miscarriage. Patients assessed and discharged solely by an accident and emergency doctor were included. The objectives were to determine how many patients presented with heavy or repeated bleeding, or abdominal pain, and if the guidelines for the use of rhesus prophylaxis were followed.

Results -Altogether 112 women fulfilled the criteria for inclusion. Sixty patients $(53.5 \%)$ presented with abdominal pain, $59(52.6 \%)$ with heavy bleeding, and $16(14.2 \%)$ with abdominal pain and heavy bleeding. Twenty four patients $(21.4 \%)$ presented with intermittent bleeding greater than 72 hours' duration. Eighty three patients $(74.1 \%)$ presented with either abdominal pain, heavy or recurren bleeding. Blood for grouping was taken in 36 patients $(32.1 \%)$. Rhesus status was documented in 15 patients $(13.3 \%)$, of whom six were rhesus negative. Four rhesus negative patients were given anti-D immunoglobulin Ninety seven patients $(86.6 \%)$ were discharged without rhesus status being checked, 15 rhesus negative patients were not offered anti-D immunoglobulin; 19 patients were rhesus negative.

Discussion - It should be mandatory to document rhesus status. In a realistic context regarding the practical management of such patients in the accident and emergency department, anti-D immunoglobulin should still be offered to all non-immune rhesus negative women presenting with a threatened miscarriage less than 12 weeks' gestation.

Local anaesthesia for peripheral venous cannulation in the accident and emergency department-results of a prospective randomised controlled trial

K CUNNINGHAM, P SUGARMAN, A M T GOOD

Accident and Emergency Medicine Department, Royal Liverpool University Hospital, Prescot Street, Liverpool L7 8XP

Background-Previous work, mainly from studies performed in anaesthetic departments, has suggested that subcutaneous infiltration with local anaesthetic significantly reduces the pain of venous cannulation. However, local anaesthetic infiltration before venous cannulation is not routine practice in many accident and emergency departments in the UK.

Aims-To evaluate whether local anaesthetic infiltration significantly reduces the pain of venous cannulation in an $\mathrm{A} \& \mathrm{E}$ setting.

Methods - A convenience sample of 101 patients requiring venous cannulation was prospectively randomised to two treatment groups. The experimental group received subcutaneous lignocaine before venous cannulation while the control group was cannulated without pretreatment. An 18G cannula was used in all cases, and all patients were treated by a consultant or middle grade doctor. A 100 $\mathrm{mm}$ visual analogue pain scale (VAPS) was used to record a pain score after completion of cannulation. Success or failure at first cannulation attempt was also recorded.

Results-A total of 101 patients were enrolled, 48 received subcutaneous lignocaine (six failed cannulations at first attempt) and 52 were cannulated without (three failed cannulations). One patient was withdrawn due to a possible allergic reaction to lignocaine. The median VAPS of venous cannulation after 
subcutaneous infiltration ( $8 \mathrm{~mm}$, interquartile range $2-14 \mathrm{~mm}$ ) did not differ significantly (at the 0.05 level, Mann-Whitney) from the median VAPS without treatment $(11 \mathrm{~mm}$, interquartile range $2.25-26 \mathrm{~mm}$ ).

Conclusions - The use of subcutaneous lignocaine infiltration does not make the experience of venous cannulation with an $18 \mathrm{G}$ cannula significantly less painful than cannulation without local anaesthetic. This is in contrast to the results of previous studies. The success rate of cannulation is unaffected by the use of local anaesthetic. These findings and the added time and resources involved indicate that routine use of subcutaneous lignocaine prior to venous cannulation is unnecessary.

Factors influencing compliance to antibiotics prescribed in accident and emergency

F LAM $^{\star}$, F STEVENSON ${ }^{\star \star}$, N BRITTEN ${ }^{\star \star}$, I STELL ${ }^{\star}$ ${ }^{\star}$ Accident and Emergency Department, Bromley Hospital, Kent, ** Department of General Practice and Primary Care, Guy's, King's and St Thomas' School of Medicine, 5 Lambeth Walk, London SE11 6SP

Studies in general practice show that levels of compliance necessary to meet therapeutic objectives occur about half the time, and may be affected by patients' perceptions of the consultation, and their views on medicines in general.

This self report questionnaire study investigated compliance to antibiotics in patients attending the A\&E department, and explored the relationship to these influencing factors. The questionnaire asked for timings of doses taken and views on the consultation and on medicines in general.

Postal questionnaires were sent to patients who had received antibiotics to take home in two 10 day periods over 15 years. Two telephone reminders were made, and a sample of non-responders was interviewed by telephone.

Questionnaires were returned by $113 / 202$ patients $(56 \%)$. Patients were divided into three compliance categories: 78 indicated they had taken $>80 \%$ of prescribed doses (category A), 25 that they had taken $<80 \%$ of doses (B), and 10 had taken no doses (C). Responses to the questions were scored from 1 "strongly agree" to 5 "strongly disagree" (see table 8 ).

In conclusion $31 \%$ of patients admitted to degrees of non-compliance to antibiotics that were potentially clinically significant. Those

Table 8

\begin{tabular}{|c|c|c|c|c|c|}
\hline \multirow[b]{2}{*}{ Question (abbreviated) } & \multicolumn{3}{|c|}{ Compliance category ${ }^{*}$} & \multirow[b]{2}{*}{$p$ Value } & \multirow{2}{*}{$\begin{array}{l}p \text { Value } A \\
v C\end{array}$} \\
\hline & $A$ & $B$ & $C$ & & \\
\hline \multicolumn{6}{|l|}{ Perception of the consultation } \\
\hline Doctor was friendly & 1.69 & 1.68 & 2.10 & 0.77 & 0.15 \\
\hline Doctor understood my problem & 1.90 & 1.96 & 2.20 & 0.66 & 0.30 \\
\hline I expected a prescription & 2.56 & 2.88 & 3.70 & 0.21 & 0.002 \\
\hline Doctor explained the treatment & 2.41 & 2.40 & 3.20 & 0.78 & 0.028 \\
\hline Doctor explained side effects & 3.46 & 3.88 & 3.50 & 0.18 & 0.66 \\
\hline Concerned about side effects & 3.67 & 3.40 & 3.10 & 0.34 & 0.03 \\
\hline There were too many tablets & 3.97 & 3.92 & 3.20 & 0.50 & 0.005 \\
\hline Satisfied with consultation & 1.90 & 2.20 & 2.50 & 0.30 & 0.11 \\
\hline \multicolumn{6}{|l|}{ Attitude to medicines in general } \\
\hline Doctors use too many & 3.51 & 3.36 & 3.20 & 0.36 & 0.41 \\
\hline Should stop them from time to time & 3.21 & 3.36 & 3.60 & 0.25 & 0.29 \\
\hline Medicines are addictive & 3.35 & 3.44 & 3.20 & 0.52 & 0.50 \\
\hline Natural remedies are safer & 3.00 & 2.64 & 2.90 & 0.07 & 0.76 \\
\hline Medicines do more harm than good & 3.83 & 3.76 & 3.70 & 0.65 & 0.55 \\
\hline All medicines are poisons & 3.85 & 3.96 & 3.40 & 0.36 & 0.08 \\
\hline Doctors trust medicines too much & 3.55 & 3.08 & 3.20 & 0.05 & 0.13 \\
\hline More time with patients, fewer prescriptions & 2.95 & 2.64 & 2.70 & 0.23 & 0.48 \\
\hline
\end{tabular}

${ }^{\star}$ Mean score.

patients who took none of the prescribed medicine tended to have a poorer perception of the consultation, and not to have expected to receive medication. Exploring views on receiving medicines, and more effective consultations, may improve compliance.

Per rectal diazepam in children with spasmodic torticollis

JOYDIP BANERJEE, PETER N GOODE

Accident and Emergency Department, Newcastle upon Tyne NHS Trust

Diazepam is prescribed in children with muscle spasticity and seizures. Per rectal route is used widely for treating convulsive episodes in children and it is safe and effective. Children with spasmodic torticollis are frequently unable to take medicines orally because of inability to alter their head posture due to pain and stiffness affecting one of the sternocleidomastoid muscles. A study was carried out to test the hypothesis that per rectal diazepam could be safe and effective in children with spasmodic torticollis. Three children, aged 4 5 , and 6 years, who presented to the A\&E department between August 1997 and May 1998 with non-traumatic, spontaneous torticollis were included in the study. They were al very anxious and were unable to swallow ora medication due to neck pain and inability to alter their head position. There was no history of trauma and none of them had any contributory causes. They were all normally fit and well. Each of them was treated with 5 $\mathrm{mg}$ of per rectal diazepam after seeking consent from them and their parents. Their conscious state, pulse, and blood pressure were monitored by a RSCN every 15 minutes for one hour. There was no alteration in conscious level in any of the children. By the end of this period all of them recovered a complete range of neck movements, had significantly diminished pain, and were comfortable enough to be discharged home on oral analgesia with advice to continue neck mobilisation and to return if there were any problems. No routine follow up was arranged and there were no returns. It can be concluded that per rectal diazepam is an acceptable, effective, and safe treatment for the above condition. A large study is being set-up to corroborate these findings and to see if it reduces the need for oral analgesia.
Compliance category ${ }^{\star}$

\section{Posters: Airway}

Rapid sequence intubation: a survey of senior and middle grade accident and emergency staff in Scotland

C A GRAHAM ${ }^{\star}$, S B THAKORE ${ }^{\star \star}$, A P MATTICK ${ }^{\star \star \star}$, E DOCHERTY ${ }^{\star \star \star \star}$, G M WARES ${ }^{\star \star \star \star \star \star}$

Accident and Emergency Departments, ${ }^{*}$ Crosshouse Hospital, Kilmarnock, ${ }^{\star \star N}$ Ninewells Hospital, Dundee, ${ }^{* * *}$ Royal Infirmary of Edinburgh, $\star \star * * *$ Aberdeen Royal Infirmary, ${ }^{\star * * * * \text { Glasgow }}$ Royal Infirmary

Background-Rapid sequence intubation (RSI) in A\&E departments can be performed by an anaesthetist or an appropriately trained and experienced $\mathrm{A} \& \mathrm{E}$ doctor. As part of a larger project, this survey was done to ascertain the level of anaesthetic experience of $\mathrm{A} \& \mathrm{E}$ doctors and their degree of confidence in performing RSI.

Method-Structured questionnaire sent to senior and middle grade $\mathrm{A} \& \mathrm{E}$ doctors in seven teaching hospitals in Scotland in spring 1999. Results-Forty seven completed questionnaires were returned (response rate $78 \%$; 47/60). Four doctors possessed the FRCA and a further six possessed the DA(UK). Altogether $98 \%$ of all doctors surveyed rated their airway assessment skills as reasonable or better; $21 \%$ felt their confidence in using drugs to facilitate intubation was low or very low; $72 \%$ of $\mathrm{A} \& \mathrm{E}$ doctors had personally given drugs to facilitate intubation within the last six months; $47 \%$ had given drugs within the preceding month to facilitate intubation, $19 \%$ had not given drugs for more than a year. Doctors who possessed the FRCA or $\mathrm{DA}(\mathrm{UK})$ were more confident at assessing airways and giving anaesthetic and paralysing drugs and were more likely to have given drugs within the last month $(9 / 10)$. There were no differences between those with other postgraduate qualifications. Consultants were generally more confident compared with trainees; likewise, specialist registrars were more confident than experienced senior house officers. There would therefore seem to be a clear training and/or experience effect with these techniques.

Conclusion-There is a wide range of confidence in the skills of RSI among senior and middle grade $\mathrm{A} \& \mathrm{E}$ doctors. A\&E doctors would appear to be using these techniques on a regular basis in Scotland contrary to popular belief.

Do all trauma patients with a Glasgow coma scale score of 8 or less need endotracheal intubation?

C R FITZSIMMONS, C MOULTON, D W YATES ON BEHALF OF THE TRAUMA AUDIT AND RESEARCH NETWORK

Trauma Audit and Research Network, Clinical Sciences Building, Hope Hospital, Eccles Old Road, Salford, Manchester M6 8HD

Background - Glasgow coma scale score (GCS) is often used as an indicator of the need to endotracheally intubate patients. This is based on an assumed loss of airway muscle tone as conscious level falls, with subsequent airway obstruction and hypoxia. Hypoxia has been shown to be an important cause of secondary deterioration in brain injured patients. However a definite relation between GCS and hypoxia remains unproved. Patients may be intubated unnecessarily as a result. Emergency endotracheal intubation is not without significant risks to the patient. 
Objective - To relate oxygen saturation $\left(\mathrm{SaO}_{2}\right)$ to GCS in trauma patients and to assess the value of using GCS as a guide to hypoxia and the need for endotracheal intubation.

Study design and patients-Retrospective analysis of a large UK trauma database. Altogether 4583 non-intubated trauma patients ( $4 \%$ of total database) were included who had documented $\mathrm{SaO}_{2}$ and GCS from both at scene and in the emergency department. Mean age was 42 . Mean injury severity score (ISS) was 12.

Method- $\mathrm{SaO}_{2}$ was assessed as poor (60$89 \%)$, low $(90-95 \%)$, or normal $(96-100 \%)$ and related to three groups of GCS ( 15-13, $12-9$, and $\leqslant 8$ ). Data were further analysed according to the ISS (ISS $<16$ and ISS $>15$ ) and place of assessment (at scene and in the emergency department).

Results - Of all seriously injured comatose patients, $52 \%$ were normally saturated at scene. By time of arrival at the emergency department this figure was $69 \%$. In less seriously injured comatose patients the figures were $61 \%$ and $85 \%$ respectively. These improvements were seen following simple airway opening manoeuvres. In every subgroup there was a trend towards increasing hypoxia as the GCS fell. Correlation of $\mathrm{SaO}_{2}$ with GCS was very weak but highly significant.

Conclusions - The majority of comatose patients actually have adequate oxygenation. Obtaining a GCS can be difficult in certain cases whereas the widespread introduction of pulse oximetry allows simple measurement of $\mathrm{SaO}_{2}$. It is more logical to base indications for endotracheal intubation on clinical assessment and $\mathrm{SaO}_{2}$ than on GCS. Further, it is safer to adopt this approach than subject patients to the risks of complications should intubation attempts be made inappropriately.

Difficult airway equipment in English emergency departments

TOM MORTON

Accident and Emergency Department, Southampton General Hospital, Tremona Road, Southampton SO16 6YD

Objective-To determine the availability of equipment for the management of the difficult airway in the emergency department.

Design-Telephone survey.

Setting-All 197 adult emergency departments in England that have an annual attendance of more than 20000 new patients.

Results-All departments responded to the survey. One hundred and ninety seven $(100 \%)$ held a curved adult laryngoscope blade, 126 $(64 \%)$ had a straight adult blade, $161(82 \%)$ had an endotracheal tube stylet, $196(99 \%)$ had a gum elastic bougie, and $27(14 \%)$ held a McCoy laryngoscope.

Of alternative devices for ventilation, laryngeal mask airways were kept by $129(65 \%)$ departments, the intubating laryngeal mask by $13(7 \%)$, an oesophageal-tracheal twin lumen airway by $36(18 \%)$, and transtracheal jet ventilation apparatus by $124(63 \%)$. Twenty one (11\%) departments did not stock an alternative ventilation device.

Of alternative devices for intubation, a bronchoscope (rigid or flexible) was available in $10(5 \%)$ and the lighted stylet in four $(2 \%)$ departments. A retrograde intubating kit was held by $15(8 \%)$, and a surgical airway kit in a total of $193(98 \%)$ of units.

One hundred and forty six (74\%) departments kept a device for the measurement of end tidal carbon dioxide and $97(49 \%)$ units considered that their airway equipment was kept in a portable storage unit.

Conclusions - A wide variation exists in the types of equipment kept in English emergency departments for the management of the difficult airway. Difficult intubation is more likely to occur in the emergency department than in the operating room. It is therefore essential to have a range of alternative airway devices immediately available in the resuscitation room of all emergency departments. This is not the case in England.

\section{Posters: Delivery of Care}

Do routine diabetes reviews in general practice keep individuals with diabetes out of accident and emergency?

$S$ W GOODACRE ${ }^{\star}$, E C GOYDER ${ }^{\star \star}$, J L BOTHA ${ }^{\star \star}$, G G BODIWALA *

${ }^{*}$ Department of Accident and Emergency Medicine, Leicester Royal Infirmary NHS Trust, Leicester, and ${ }^{\star *}$ Department of Epidemiology and Public Health, University of Leicester, Leicester

Objectives-To identify predictors of acciden and emergency (A\&E) attendance by subjects with diabetes and determine whether routine diabetes review in general practice is associated with a reduced probability of attendance. Design - A historical cohort of all subjects with diabetes registered with five randomly selected general practices was identified using repeat prescribing data, practice registers, and information on records. Information on use of $\mathrm{A} \& \mathrm{E}$ and potential explanatory variables were collected from general practice records, postal questionnaires, and an $\mathrm{A} \& \mathrm{E}$ database and the relation between potential explanatory variables and attending A\&E was examined.

Setting - The Leicester Royal Infirmary A\&E department.

Subjects— 554 subjects with diabetes.

Main outcome measurement- $\mathrm{A} \& \mathrm{E}$ attendance between 1991 and 1995.

Results-Complete information was available for 475 (86\%), of whom $41 \%$ had attended A\&E. The main predictors of attendance were indicators of morbidity, such as treatment with insulin (adjusted odds ratio (OR) 1.20 $95 \%$ confidence interval (CI) 1.22 to 2.70 ) and the number of other drugs prescribed (adjusted OR 1.81, 95\% CI 1.10 to 1.50 ). Home owners were less likely to have attended $\mathrm{A} \& \mathrm{E}$ than those in rented accommodation (adjusted OR $0.76,95 \%$ CI 0.61 to 0.94 ). After adjustment for morbidity, a diabetes review in general practice was associated with an increased probability of attendance, while a visit to outpatients was associated with a decreased probability of attendance, but these associations were not statistically significant. Conclusions - The main predictors of A\&E attendance were insulin treatment, chronic co-morbidity, and not being a home owner This study provides no support for the hypothesis that subjects with diabetes who

Table 9 Process of care and $x$ rays clinically important errors

\begin{tabular}{lllll}
\hline & AEE No (\%) & MIU No (\%) & $\chi^{2}$ & p Value \\
\hline History, mechanism of injury & $1(0.07)$ & $0(0)$ & & 1 \\
Past, medical history & $31(2.3)$ & $1(0.1)$ & 15.22 & $<0.0001$ \\
Examination & $24(1.8)$ & $19(2.3)$ & 0.74 & 0.39 \\
Treatment, advice & $56(4.2)$ & $17(2.1)$ & 6.86 & 0.009 \\
Follow up & $44(3.3)$ & $15(1.8)$ & 4.01 & 0.045 \\
Total number of patients analysed & $1337(100)$ & $816(100)$ & & \\
$x$ Ray requests & $224(16.8)$ & $107(13.1)$ & & 0.02 \\
$x$ Ray interpretation & 10 & $6(0.7)$ & & \\
\hline
\end{tabular}

attend their general practices for routine attend $\mathrm{A} \& \mathrm{E}$.

Clinical and economic impact of a chest pain assessment unit

$\mathrm{K}$ R RICHELL HERREN, $\mathrm{K}$ MACKWAY-JONES, C R RICHARDS, J EASTHAM, M JAMES

Department of Emergency Medicine, Manchester Royal Infirmary, Oxford Road, Manchester M13 9WL

The aim of chest pain assessment units is twofold: firstly to prevent patients with myocardial infarction being discharged from the emergency department. Secondly to effectively rule out myocardial damage early, allowing safe discharge. A six hour protocol based on CK-MB measurements and ST segment monitoring is safe and sensitive. The aim was to assess the impact of such a service on the clinical management and health economics of chest pain in the emergency department.

Cases were collected prospectively before the implementation of the service, 1 May 1997 to 31 July 1997 and six months after the implementation of the service, 1 May 1998 to 31 July 1998; 156 cases were identified in 1997 and 170 in 1998

Cases were classified blindly using the Goldman MI risk filter in to low and moderate risk. The two groups had similar proportions of men, moderate risk cases, and cases with previous history of ischaemic heart disease.

Cases were assessed blindly for adequacy of the MI screen. To be considered adequate a MI screen had to have a reported sensitivity of $95 \%$ or greater. This included a completed chest pain assessment protocol, completed World Health Organisation MI screen in moderate risk cases and low risk cases with a 24 hour MI screen.

In 1997,125 cases $(80.1 \%)$ did not receive an adequate AMI screen and in 1998, 55 cases did not receive an adequate AMI screen $(32.4 \%)$ a significant improvement in the quality of service. Health economic data were collected and showed a significant drop in the costs around each effective AMI screen.

Prospective observational study of minor injuries care in accident and emergency department versus minor injuries unit

M SAKR, J ANGUS, A SAUNDERS, J WARDROPE

Accident and Emergency Department, Northern General Hospital, Herries Road, Sheffield S5 $7 A U$

Aim-To investigate the processes of care and treatment provided to patients with minor injuries presenting to the $\mathrm{A} \& \mathrm{E}$ department and compare it with similar group of patients presenting to the same hospital after closure of the department with the provision of nurse led minor injuries unit (MIU).

Patients - A total of 1500 patients over the age of 16 presenting with minor injuries to $\mathrm{A} \& \mathrm{E}$ department, compared with 1355 patients reviews, in an urban setting, are less likely to 
Table 10 Waiting and department times

\begin{tabular}{llcl}
\hline & $A \mathcal{E} E$ & MIU & $p$ Value \\
\hline Waiting time & 56.5 & 21.8 & $<0.0001$ \\
Department time & 94.1 & 54.2 & $<0.0001$
\end{tabular}

presenting to the MIU that replaced the department were studied.

Setting - A large urban teaching hospital A\&E department in 1996, and its successor MIU in 1997.

Design-A prospective observational study with double assessment of the patient (clinical and researcher). These two assessments were compared using standard proformas. On completion of the study the groups were compared.

Main end points-Comparison between the clinical assessment and the research assessment of history taking, examination, use of $x$ rays, $x$ ray interpretation, treatment, follow up, and advice.

Results - The provisional results from analyses of 1337 patients from the A\&E department, and 816 from the MIU are shown in tables 9 and 10 . The remaining results will be available soon.

When compared against a rigorous standard of an experienced A\&E clinician using standardised proformas there were statistically significant differences in the accuracy of medical history taking, in treatment, and in $x$ ray requesting in favour of nurse practitioners working in the MIU. Waiting and department times were also significantly shorter for patients attending the MIU. There were no differences in documenting mechanism of injury, examination, or $x$ ray interpretation.

Conclusions-The establishment of nurse practitioner led MIU has provided fast track for patients presenting with minor injuries. The quality of clinical care was even better in some aspects.

Comparison of medical admissions by an accident and emergency clinician and an on-call medical team

ROSS MURPHY ${ }^{\star}$, CHARMAINE ECKERSLEY ${ }^{\star \star}$, PETER DRISCOLL ${ }^{\star \star \star}$

${ }^{\star}$ Accident and Emergency Department, Trafford General Hospital, Manchester M41 5SL, ${ }^{\star \star} E f-$ fective Practice Unit, Trafford General Hospital, Manchester M41 5SL, and ***Accident and Emergency Department, Hope Hospital, Salford M6 $8 H D$

Objectives-To compare the A\&E times of medical patients admitted by an A\&E clini cian with the A\&E times of medical patients admitted by an on-call team. To compare the time these patients spend waiting for a bed with the two hour standard recommended by the NHS patient's charter.

Method-A retrospective data collection of all medical patients presenting to the $A \& E$ department at Trafford General Hospital during a six week period in June/July 1999. Medical patients seen by the $A \& E$ staff grade are admitted directly to the ward whereas patients seen by the rest of the A\&E team are referred to the medical team on-call for admission. Time from triage to a decision on admission and total time spent on a trolley in A\&E are recorded by the nursing staff.

Results - A total of 34 patients were admitted directly; 142 patients were admitted after referral to the on-call team. The patients in both groups were comparable in terms of the times at which presentation occurred and the subsequent diagnosis and length of hospital stay.

Conclusions-Medical patients take up a large amount of time, personnel, trolley space, and consequently resources in $\mathrm{A} \& \mathrm{E}$ departments. Much less time is spent in A\&E and NHS patient's charter standards are more likely to be met if experienced members of the A\&E team admit medical patients. 